\title{
Managing Water Supply and Demand to Achieve Economic and Environmental Objectives: Application of Mathematical Programming and ANFIS Models
}

\section{Mostafa Mardani Najafabadi ( $\nabla$ m.mardani@asnrukh.ac.ir )}

Agricultural Sciences and Natural Resources University of Khuzestan, Mollasani, Iran

Abbas Mirzaei

Agricultural Sciences and Natural Resources University of Khuzestan, Mollasani, Iran https://orcid.org/0000-0003-3161-3099

Hassan Azarm

Shiraz University

Siyamak Nikmehr

Shiraz University

\section{Research Article}

Keywords: Water integrated management, Water supply, Water demand

Posted Date: June 7th, 2021

DOI: https://doi.org/10.21203/rs.3.rs-465907/v1

License: (c) (i) This work is licensed under a Creative Commons Attribution 4.0 International License.

Read Full License 


\section{Managing water supply and demand to achieve economic and environmental objectives: Application of mathematical programming and ANFIS models}

Detail of the each author with his contribution in this paper is as under:

1. (Corresponding author)

First name: Mostafa

Last name: Mardani Najafabadi

Academic rank: Department of Agricultural Economics, Faculty of Agriculture Engineering and Rural Development, Agricultural Sciences and Natural Resources University of Khuzestan, Mollasani, Iran.

E-mail address: m.mardani@asnrukh.ac.ir

Postal Code: 6341773637

Adders: Iran, Kuzestan county, Mollasani city, Agricultural Sciences and Natural Resources University of Khuzestan.

2.

First name: Abbas

Last name: Mirzaei

Academic rank: Department of Agricultural Economics, Faculty of Agriculture Engineering and Rural Development, Agricultural Sciences and Natural Resources University of Khuzestan, Mollasani, Iran.

E-mail address: amirzaei@asnrukh.ac.ir, mabbas1369@gmail.com

Postal Code: 6341773637

Adders: Iran, Kuzestan county, Mollasani city, Agricultural Sciences and Natural Resources University of Khuzestan.

3.

First name: Hassan

Last name: Azarm

Academic rank: Ph.D. student, Department of Agricultural Economics, Shiraz University, Shiraz, Iran

E-mail address: hassan_azarm@yahoo.com

4.

First name: Siyamak

Last name: Nikmehr

Academic rank: Ph.D. student, Department of Agricultural Economics, Shiraz University, Shiraz, Iran

E-mail address: s_nikmehr@yahoo.com 


\title{
Managing water supply and demand to achieve economic and environmental objectives: Application of mathematical programming and ANFIS models
}

\begin{abstract}
Integrated management of water supply and demand has been considered by many policymakers and due to its complexity, the decision makers have faced many challenges. In this study, we proposed an efficient framework for managing water supply and demand in line with the economic and environmental objectives of the basin. To design this framework, a combination of ANFIS and multi-objective augmented $\varepsilon$-constraint programming models and TOPSIS were used. First, using hydrological data from 2001 to 2017, the rate of water release from the dam reservoir was estimated with the ANFIS model; afterwards, its allocation to agricultural areas was performed by combining multi-objective augmented $\varepsilon$-constraint models and TOPSIS . To prove the reliability of the proposed model, the southern Karkheh basin in Khuzestan province, Iran, was considered as a case study. The results showed that this model is able to reduce irrigation water consumption and improve its economic productivity in the basin.
\end{abstract}

Keywords: Water integrated management, Water supply, Water demand.

\section{Introduction}

Water resources management is one of the most important challenges of the present century and has caused major global concerns (Steusloff, 2010; Flach et al., 2020). In recent years, due to the extensive agricultural activities, the demand for surface and groundwater resources has increased significantly, exacerbating the scarcity of water resources (Mishra et al., 2016). 
Water scarcity has posed several challenges to achieving food security, and these obstacles become far more severe in developing countries (FAO, 2015). In fact, increased water demand due to population growth, economic development, pollution of water resources, and reduced groundwater and surface water quality on the one hand, and decreasing water supply due to unsustainable management of these resources, on the other hand, have become important issues in many countries (Liu et al., 2017; IPCC, 2014; Jeunesse et al., 2015). Therefore, the sustainable use of water resources is critical for maintaining food security, environmental quality, and the necessary resources for appropriate economic growth and development .

Decision makers encounter many challenges in water resources management and have to decide on the allocation of scarce water supply. This allocation should be such that the economic objectives of agricultural activity are achieved along with environmental sustainability (Forni et al., 2016). All the mentioned factors have led to imbalance in water supply and demand. In other words, since the economic supply of water is always limited and its demand is continuously increasing, it is difficult to plan for the optimal use of water resources (Gao et al., 2017). Competent management of the utilization of the existing water resources and facilities, called water supply and demand management approach, can make this possible (Allawi et al., 2019). Iran is located in one of the least water-rich regions of the world and often experiences severe droughts. Numerous studies have shown that due to the recent population growth, urbanization, industrialization, agricultural expansion and climate change, the country is currently facing a serious water crisis (Madani et al., 2016; Zamani et al., 2019; Boazar et al., 2019). As a result, comprehensive water management has become the main concern of community members, experts, and managers (Hadizadeh et al., 2018). 
Rivers and surface waters are raised as one of the main sources of water supply and transfer for various uses (Enrique, et al., 2007). Reservoir dams are highly important sources of storage and regulation of surface water, runoff, and floods (Qiu et al., 2020); however, due to fluctuations in river discharge and reservoir capacity limit, the time distribution between the inflow to reservoirs and downstream water requirements have posed some difficulties (Srinivasa Prasad et al., 2013). Accordingly, extracting the operation rules of dams is one of the essential issues in water supply management, especially surface water resources. Lack of planning for the amount of water released from the reservoir leads to problems such as water shortage during drought, instability of agricultural production downstream of dams, urban water rationing in dry seasons, and environmental problems. In this regard, the extraction of optimal exploitation rules has received more attention from researchers (Mehta and Jain, 2009; Hadiyan et al., 2020).

Surface water resources in Iran play a major role in meeting the water needs of urban, agricultural, and industrial sectors. Nonetheless, over the recent years, due to irregular rainfall, continuous droughts, and uncertainty in water supply, management of existing water resources and facilities has become all the more important (Stålnacke and Gooch, 2010; Karimi and Ardakanian, 2010). Many studies have shown that due to mismanagement and lack of comprehensive planning, the water resources crisis in this country is increasingly growing (Madani, 2014; Zargan et al., 2016; Fani et al., 2016). Therefore, reforming the existing management policies is necessary to dealing with this crisis and optimizing the outflow of reservoirs is an important step in decision making regarding water resources management (Hadiyan et al., 2020).

Due to the uncertainty concerning the variables of reservoir operation, in many studies, the theory of fuzzy sets has been used to extract the operation rules of these reservoirs (Suryanarayana and Kemkar, 2014). Based on the results of these studies,the Fuzzy Inference System (FIS) is more in 
line with the real world as it dealsthe uncertainty conditions in reservoir operation models (ElShafie et al., 2007; Soltani et al., 2010; Ranković et al., 2012; Sedeño-Díaz and López-López 2016; Kambalimath and Deka, 2020). Some researchers have proposed the Artificial Neural Networks (ANNs) method in relation to water resources management due to the wide changes in input variables and structures and learning algorithms (Zamen et al., 2019; Maddah et al., 2019; Farzaneh-Gord et al., 2020; Nasirzadehroshenin et al., 2020). High accuracy of forecasting, suitable generalizability, and low computational costs are among the advantages of this method (Coulibaly et al., 2000; Kambalimath \& Deka, 2020).

Accordingly, the combination of FIS with ANNs as Adaptive Neuro-Fuzzy Inference System (ANFIS) has been used in various studies to extract the optimal rules of reservoir operation (Safavi et al., 2013).

The ANFIS model uses a neural network learning algorithm and fuzzy logic for nonlinear mapping between input and output space. This model has both the advantages of FIS and the ability to learn neural networks; therefore, it has a higher capability compared to ANNs or FIS separately (Mehta and Jain, 2009; Safavi et al., 2013; Khadr et al., 2014; Yaseen et al., 2017; Ashrafi et al., 2017). In addition, in agricultural production systems, uncertainty related to major water supply sources has a significant effect on the cropping pattern and farmers' income (Guerrero-Baena et al., 2019). In this regard, farmers may opt to produce crops with low gross profit and capital accumulation in the cropping pattern due to the growing concerns about the uncertainty of water supply. Farmers' withdrawal from long-term investment in agriculture will reduce the productivity of the existing production resources (Lavee, 2010; Guerrero-Baena et al., 2019).

Meanwhile, the agricultural sector is the largest consumer of water in Iran with about $90 \%$ of the available water consumed there (boozar et al., 2019). On the other hand, the conflict of water 
consumption among the users of the agricultural sector and environmental services has increased competition for the use of water resources, particularly in developing countries (Allan, 2003). Accordingly, it is recommended that a policy be established for the protection and storage of water and the use of storage water for environmental purposes (Sisto, 2009). In this regard, determining the optimal cropping pattern in order to optimally allocate water resources, meet environmental needs, and maximize the gross profit of farmers can be considered as one of the appropriate solutions to this problem (Smardon, 2009; Nikouei et al., 2012; Smith et al., 2020).

There are several studies focused on determining the optimal cropping pattern that, in addition to the economic objective, have considered other objectives such as protection of water resources, reduction of the environmental pollution caused by fertilizer and pesticide consumption, and reduction of production risk (Francisco \& Mubarik, 2006; Mardani Najafabadi et al., 2019; Mirzaei and Zibaei, 2021). Providing maximum gross profit and optimal water allocation in optimizing cropping patterns are two clear objectives of many studies, including the study of Garg et al. (2014), Galan-Martína et al. (2015), and Zhang \& Guo (2016).

Due to the existence of conflicting objectives in the agricultural production system, many researchers have proposed multi-objective programming to determine the optimal cultivation pattern (Niu et al. 2016; Mirzaei and Zibaei, 2021). However, in this approach, instead of an optimal solution, a set of solutions is often obtained (Marler \& Arora, 2004).

The methods used to solve the multi-objective optimization model are very different and the most important are weighted, constrained, and multi-criteria simplex methods. The constrained method is more acceptable than other multi-objective programming solver methods (Fathipour \& SaidiMehrabad, 2018). In this method, each objective is optimized separately and others are added to the model as constraints. Through changing the values of the right-hand side of the constrained 
objectives, a set of Pareto optimal solutions can be achieved (Esmaeel Nezhad et al., 2014). Several versions of the constrained method have been used to solve linear multi-objective programming problems, one of which is the augmented $\varepsilon$-constraint method. One of the advantages of this method, unlike older versions of the constrained method, is that it extracts a set of strong efficient solutions and eliminates weak efficient ones (Pakdel et al., 2020).

In general, the aim of the present study was the simultaneous management of water supply and demand in agricultural lands of Karkheh Dam sub-basin with emphasis on economic and environmental objectives. The innovation of this study is that it analyzes the sustainable management of water resources in this basin in terms of both modeling and comprehensiveness. In this regard, ANFIS and multi-objective augmented $\varepsilon$-constraint programming models were used to determine the rate of water release and meet the mentioned objectives, respectively.

\section{Study area}

In 1998, Iran began building the largest dam on the Karkheh River. With a storage capacity of 7.5 billion cubic meters and an active storage capacity of 4.7 billion cubic meters, this dam is located northwest of Khuzestan province and was put into operation in August 2002 (Marjanizadeh et al., 2010; Masih et al., 2011). At present, this dam provides about 8.1 billion cubic meters of water requirement for 320,000 hectares of downstream agricultural land and also helps control floods in these lands (Fereidoon and Koch, 2018). Hoveyzeh Wetlands is one of the largest wetlands in West Asia and the Mesopotamian plain (the land between the Euphrates and Tigris Rivers); these wetlands are located jointly between Iran and Iraq. The eastern part of Hoveyzeh wetlands is known as Hoorolazim, located at the end of Karkheh river in Khuzestan province, Iran (2009 Haghiabi \& Mastorakis). 
South Karkheh is an important sub-basin of Karkheh River, which includes the agricultural areas of Paypol, Kowsar-Quds, Hamidiyeh, Azadegan, and Karkheh Noor (Fig. 1). Rainfall in this subbasin has been reported to be less than $150 \mathrm{~mm}$ over many years. On the other hand, most of the rainfall in winter and summer is close to zero. In other words, this sub-basin has faced severe water shortages in recent decades due to drought and irregular rainfall patterns. Irrigation of agricultural lands has also reduced water inflow to Hoorolazim wetland (Choubin et al., 2019).

In general, this wetland has undergone many changes over the recent decades. For example, in the Iran-Iraq war from 1981 to 1989 , the construction of roads in wetlands by warring parties caused the wetland to dry up. The construction of several diversion dams in the Karkheh and Tigris basins have also caused a severe reduction in the inflow of water into the wetland. Exploitation of Karkheh Dam and the drilling related to oil extraction in recent years has increased the hydrological and environmental stresses on the Hoorolazim Wetland, which has led to the drying up of a large part of the wetland. According to the above, meeting the water needs of this wetland can be very effective in restoring ecological conditions and improving its environmental performance (Ghobadi et al., 2015) . 


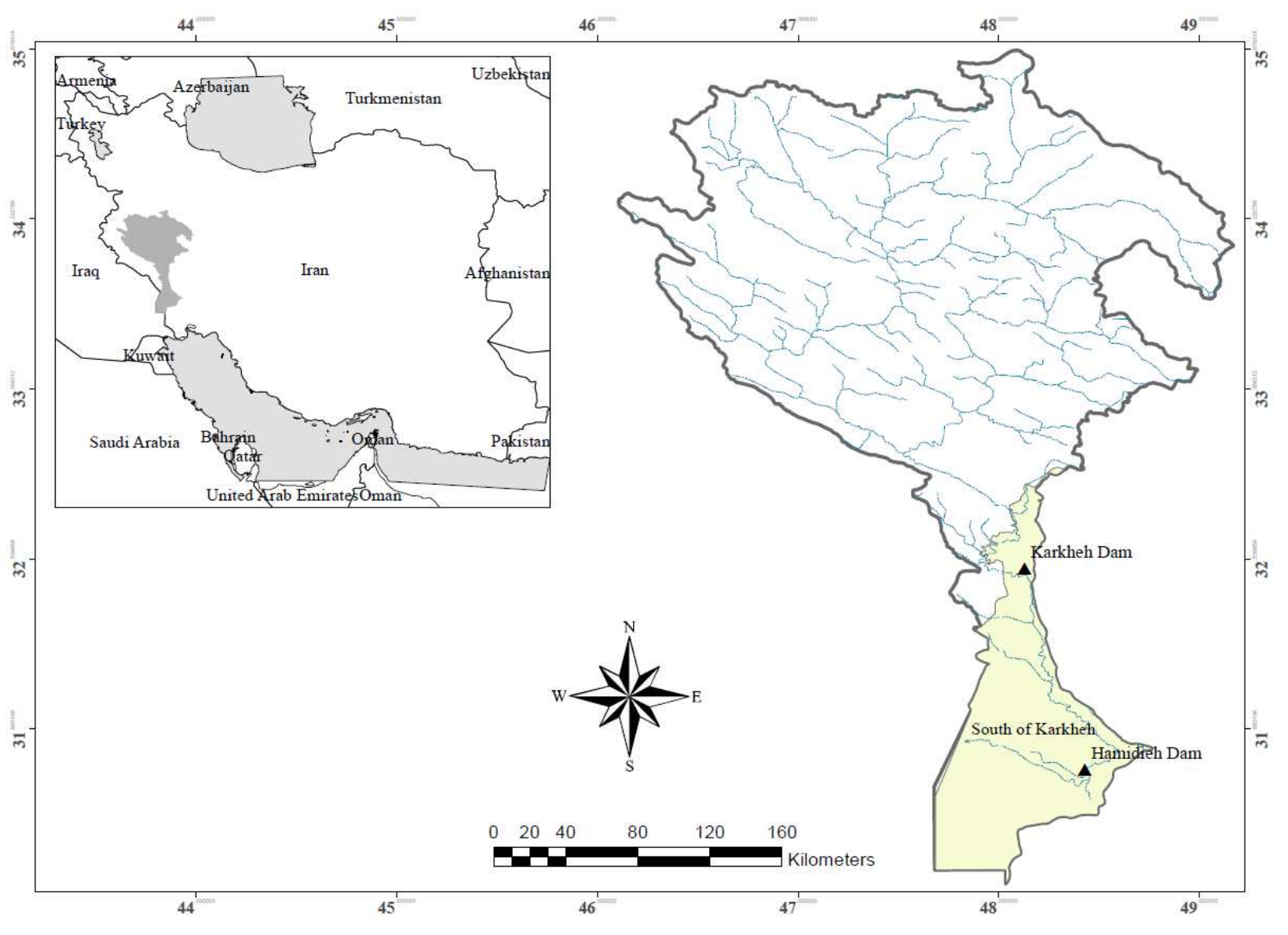

Fig. 1- Location of the South Karkheh

\section{Materials and Methods}

Fig. 2 presents the relationship among the three phases of the study for comprehensive management of water supply and demand under the Karkheh Dam (South Karkheh) basin (conceptual framework). In the first phase, the optimum and most efficient operation rules of the Karkheh dam reservoir have been extracted and the volume of the water released from this reservoir has been estimated with the ANFIS model. In the second phase, using a multi-objective augmented $\varepsilon$-constraint programming model for economic and environmental objectives, an efficient set of solutions were extracted. In the third phase, the best efficient solution was 
determined using the Technique for Order Preference by Similarity to Ideal Solution (TOPSIS), and the appropriate cropping pattern was extracted to achieve the optimal solution of the objectives. In what follows, the details of these three phases will be discussed.

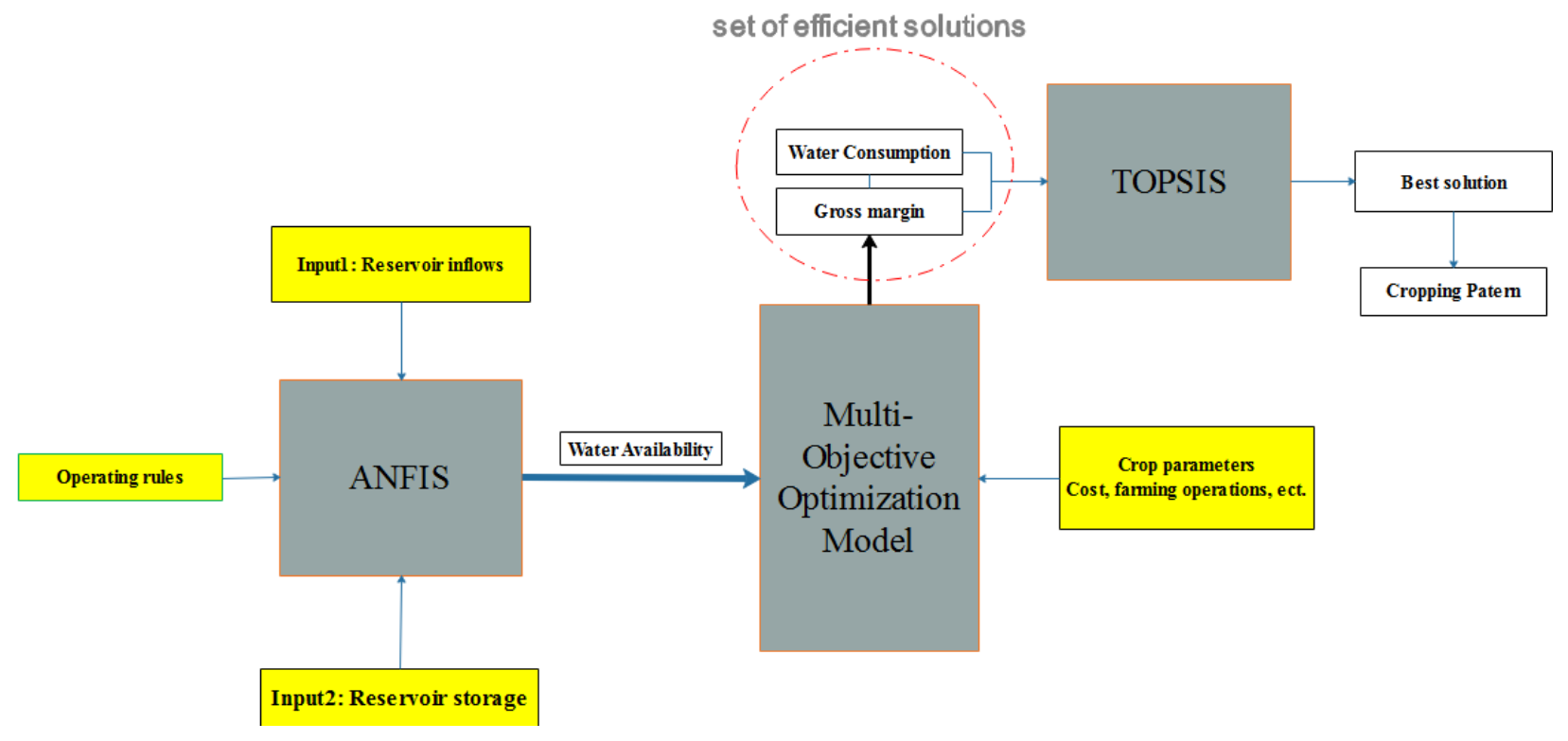

Fig. 2- Conceptual framework for water resources supply and demand management

\subsection{Adaptive neural network based on fuzzy inference system}

These types of networks, created by combining artificial neural networks and fuzzy logic, categorize and learn fuzzy rules, and fuzzy logic inferred uncertain parameters of artificial neural networks (Ebtehaj and Bonakdari, 2014; Yaseen et al., 2017). Therefore, ANFIS model has a higher capability compared to the separate application of artificial neural networks and fuzzy logic (Ashrafi et al., 2017). Three major types of ANFIS models are Mamdani, Sugeno, and Tsumoto, among which the Sugeno system is the most widely used (Mousavi et al., 2007). In fact, ANFIS system is the implementation of this system as a feed-forward network structure (Jang, 1993). Fig. 3 shows a Sugeno fuzzy system with two inputs, one output, and two rules . 


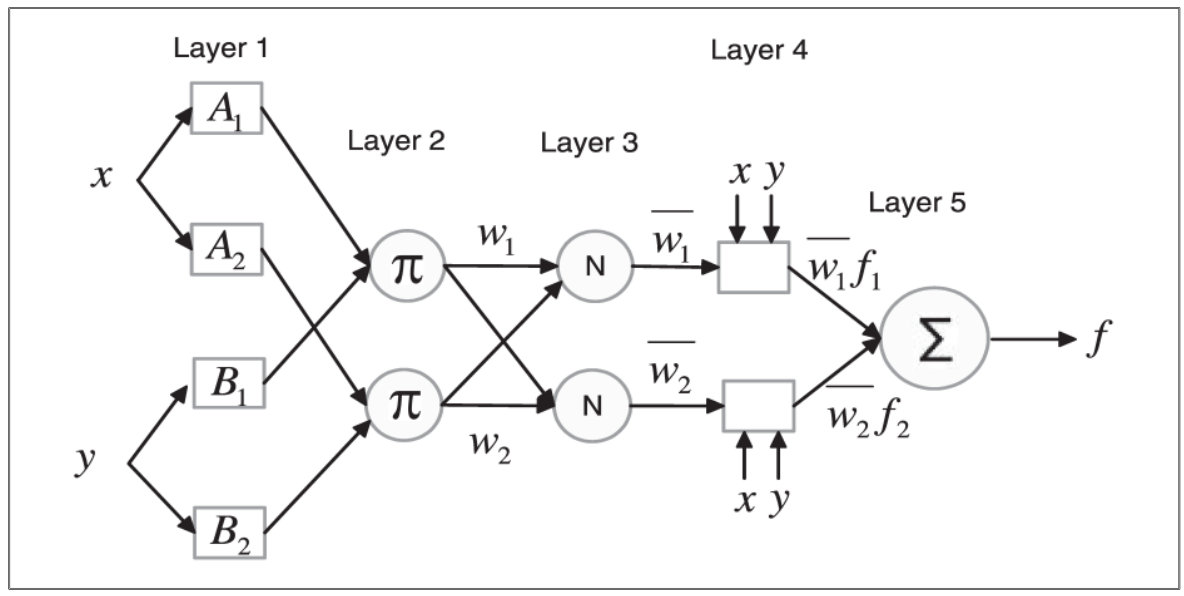

Fig. 3- Schematic structure of ANFIS network

The two inputs of the system are $x$ and $y$, its output is denoted by $f$, and the two rules of this system can be expressed as eq. (1) and (2) (Takagi \& Sugeno, 1983).

$$
\begin{aligned}
& \text { If } x \text { is } A_{1} \& y \text { is } B_{1} \text { then } f=p_{1} x+q_{1} y+r_{1} \\
& \text { If } x \text { is } A_{2} \& y \text { is } B_{2} \text { then } f=p_{2} x+q_{2} y+r_{2}
\end{aligned}
$$

According to the figure, the structure of ANFIS network consists of five layers. The first layer is the input layer and each node in it is equivalent to a fuzzy set; the output of each node is equal to the membership degree of the input variable in the fuzzy set. The parameters of each node determine the shape of the membership function of the fuzzy set of that node. Various functions, such as triangular, trapezoidal, and bell-shaped features, are used in the design of neural-fuzzy networks (Tarazkar et al., 2018).

In the second layer, the input values of each node are multiplied and the result, which is the weight of the rules, is obtained. Each node in the second layer calculates the activity degree of a rule and is represented by Eq. (3).

$$
Q_{i}^{2}=w_{i}=\mu_{A i}(x) \times \mu_{B i}(y)
$$


Where $\mu_{A i}(x)$ is the degree of membership $x$ in set $A_{i}$, and $\mu_{B i}(y)$ is the degree of membership $y$ in set $\mathrm{B}_{\mathrm{i}}$. In the third layer, nodes play an important role and determine the relative weight of the rules. Using Eq. (4), the relative weight of node i can be calculated in relation to the total weight of this layer.

$Q_{i}^{3}=\bar{w}_{i}=\frac{w_{i}}{w_{1}+w_{2}}, i=1,2$

Where $\bar{w}_{i}$ is the degree of the weight activity of the $i^{t h}$ rules. In the fourth layer, the output of each node is in the form of Eq. (5).

$Q_{i}^{4}=\bar{w}_{i} f_{i}=\bar{w}_{i} \cdot\left(p_{i} x+q_{i} y+r_{i}\right), i=1,2$

Where $p_{i}, q_{i}$, and $r_{i}$ are the adaptive parameters of this layer, also called consequence parameters. The fifth layer is the ANFIS output and each node in it calculates the final output value using Eq. (6).

In this layer, the number of nodes is equal to that of the outputs, hence equal to one in most studies. Two types of linear and constant membership functions can be used to calculate the output .

$Q_{i}^{5}=\sum \bar{w}_{n} f_{i}=\frac{\sum w_{i} f_{i}}{\sum w_{i}}$

Finally, the total output can be expressed as a linear combination of the consequence parameters according to Eq. (7).

$$
\begin{aligned}
& f=\sum \bar{w}_{i} f_{i}=\left(\bar{w}_{1} x\right) p_{1}+\left(\bar{w}_{1} y\right) q_{1}+\left(\bar{w}_{1}\right) r_{1} \\
& +\left(\bar{w}_{2} x\right) p_{2}+\left(\bar{w}_{2} y\right) q_{2}+\left(\bar{w}_{2}\right) r_{2}
\end{aligned}
$$

Two learning algorithms are usually used for training an ANFIS network: the error backpropagation and hybrid method. In this study, both algorithms were used and the results were compared. 


\subsection{Multi-objective Programming model}

The model used in the present study is a multi-objective planning model in order to maximize the gross profit of farmers and minimize water consumption to store it for wetland environmental services. In this model, the optimal combination of land allocation $\left(X_{c, a}\right)$ to crops $(c)$ and different areas $(a)$ is obtained from objective functions and technical, structural, and political constraints . Objective functions are defined as Eq. 8 and 9.

$$
\begin{aligned}
& \max Z_{1}=\sum_{c} \sum_{a} p_{c} \cdot y_{c, a} \cdot X_{c, a}-\sum_{c} \sum_{a} t c_{c, a} \cdot X_{c, a}-\sum_{c} \sum_{a} \sum_{t} w p \cdot\left(n w_{c, t} / e f_{c, a}\right) \cdot X_{c, a} \\
& \min Z_{2}=\sum_{c} \sum_{a} \sum_{t}\left(n w_{c, t} / e f_{c, a}\right) \cdot X_{c, a}
\end{aligned}
$$

These equations show the total gross profit and the amount of water used in the basin, respectively .

Where the parameters are $p_{c}$ : price per unit of crop $(c) ; y_{c, a}$ : crop yield in area $(a) ; t c_{c, a}:$ cost of production without water cost per crop $(c)$ and area $(a) ; w p$ : price per unit of consumption irrigation water; $n w_{c, t}$ : net water requirement per crop $(c)$ and month $(t)$; and $e f_{c, a}$ : efficiency of irrigation technology per crop $(c)$ and area $(a)$, and the model variables are $X_{c, a}$ : decision variable of area under cultivation per crop $(c)$ and area $(a) ; Z_{1}$ : free variable of total gross profit, and $Z_{2}$ : total amount of water consumption .

The constraints of the amount of available arable land and the amount of available irrigation water are considered in Eq. 10 and 11, respectively.

$\sum_{c} X_{c, a} \leq \operatorname{land}_{a}$

$\sum_{c} \sum_{a}\left(n w_{c, t} / e f_{c, a}\right) \cdot X_{c, a} \leq$ Water $_{t}$

The general form of the multi-objective programming model for optimizing the cropping pattern can be expressed as Eq. 12 (Francisco \& Mubarik, 2006). 


$$
\begin{aligned}
& \max z=\left(Z_{1}\left(X_{j}\right), Z_{2}\left(X_{j}\right), \ldots, Z_{h}\left(X_{j}\right), \ldots, Z_{k}\left(X_{j}\right)\right) \\
& Z_{1}(x)=Z_{1}\left(x_{1}, x_{2}, \ldots, x_{n}\right) \\
& Z_{2}(x)=Z_{2}\left(x_{1}, x_{2}, \ldots, x_{n}\right) \\
& Z_{h}(x)=Z_{h}\left(x_{1}, x_{2}, \ldots, x_{n}\right) \\
& \mathrm{M} \\
& Z_{k}(x)=Z_{k}\left(x_{1}, x_{2}, \ldots, x_{n}\right)
\end{aligned}
$$

Where $Z$ is the vector of the objective function and $Z_{i}$ is the individual objective function. $n$ is the number of agricultural products and $X_{i}$ is the area under cultivation allocated to the crop $j$.

The general form of a multi-objective model in which the h objective of the total existing objectives $\mathrm{k}$ is optimized and the remaining $\mathrm{k}-1$ is considered as a constraint can be considered as Equation 13 (Hwang and Masud, 2012):

$$
\begin{aligned}
& \max : Z_{h}\left(x_{1}, x_{2}, \ldots, x_{n}\right) \\
& Z_{1}\left(x_{1}, x_{2}, \ldots, x_{n}\right) \geq e_{1} \\
& Z_{2}\left(x_{1}, x_{2}, \ldots, x_{n}\right) \geq e_{2} \\
& \mathrm{M} \\
& Z_{h-1}\left(x_{1}, x_{2}, \ldots, x_{n}\right) \geq e_{h-1} \\
& Z_{h+1}\left(x_{1}, x_{2}, \ldots, x_{n}\right) \geq e_{h+1} \\
& \mathrm{M} \\
& Z_{k}\left(x_{1}, x_{2}, \ldots, x_{n}\right) \geq e_{k}
\end{aligned}
$$

By changing the parametric values of $e$ on the right-hand side, a set of efficient solutions is obtained. Using the multi-objective augmented $\varepsilon$-constraint programming method, strongly efficient solutions are extracted and weakly efficient ones are eliminated. For this purpose, the surplus or deficit variables are used to convert the constraints of Eq. 13 from unequal to equal (Equation 14). 


$$
\begin{aligned}
& \max \left(Z_{h}\left(x_{1}, x_{2}, \ldots, x_{n}\right)+e p s\left(s_{1}+s_{2}+\ldots+s_{h-1}+s_{h+1}+\ldots+s_{k}\right)\right) \\
& Z_{1}\left(x_{1}, x_{2}, \ldots, x_{n}\right)-s_{1}=e_{1} \\
& Z_{2}\left(x_{1}, x_{2}, \ldots, x_{n}\right)-s_{2}=e_{2} \\
& \mathrm{M} \\
& Z_{h-1}\left(x_{1}, x_{2}, \ldots, x_{n}\right)-s_{h-1}=e_{h-1} \\
& Z_{h+1}\left(x_{1}, x_{2}, \ldots, x_{n}\right)-s_{h+1}=e_{h+1} \\
& \mathrm{M} \\
& Z_{k}\left(x_{1}, x_{2}, \ldots, x_{n}\right)-s_{k}=e_{k}
\end{aligned}
$$

eps is a very small value (usually between 10-3 and 10-6).

It is worth noting that in this method, to avoid the problem of measurement scale, instead of $s_{j}$

variables in the objective function, $\frac{s_{i}}{r_{i}}$ is used, where $r_{i}$ is the range of the i-th objective function (the distance between the worst and the best target value). Therefore, the objective function can be considered as Eq. 15 .

$$
\max \left(Z_{h}\left(x_{1}, x_{2}, \ldots, x_{n}\right)+e p s\left(\frac{s_{1}}{r_{1}}+\frac{s_{2}}{r_{2}}+\ldots+\frac{s_{h-1}}{r_{h-1}}+\frac{s_{h+1}}{r_{h+1}}+\ldots+\frac{s_{k}}{r_{k}}\right)\right)
$$

This new version of the constrained method is called the augmented $\varepsilon$-constraint method.

\subsection{Selecting the final cropping pattern using TOPSIS}

From Pareto's efficient answers, it is possible to choose the best one according to the different opinions and views between decision makers and stakeholders, for which the TOPSIS has been used. In this method, the shortest distance from the ideal solution is selected as the optimum option, which includes the following steps:

1- Initially, for the best maximum and minimum criteria, the highest and lowest values are known as ideal solutions, respectively .

2- In this step, for the best maximum and minimum criteria, the lowest and highest values are known as anti-ideal solutions, respectively . 
3- In the last step, the relative closeness to the ideal solution index (CI) is calculated for each alternative using Equation 16.

$C I=\frac{(R)^{-}}{(R)^{+}+(R)^{-}}$

Where $R^{-}$and $R^{+}$are the distances of each solution from the anti-ideal and ideal solution, respectively. Of note, this method is classified as a compromise method.

\section{Results and Discussion}

In the present study, river inflow and reservoir water storage were considered as the input of the fuzzy inference system and the model results were considered as the water released from the reservoir (Safavi et al., 2013; Tarazkar et al., 2018). For this purpose, the monthly data of input and output variables from 2001 to 2017 were used.

Fig. 4 shows the trend of changes in inflow, storage, and release volume from the reservoir. Investigation of the trend of changes in input and output variables shows that during the years 2008 to 2015, inflow, storage, and release volume from the reservoir severely decreased. Therefore, it can be concluded that drought prevailed in this basin during these years. 


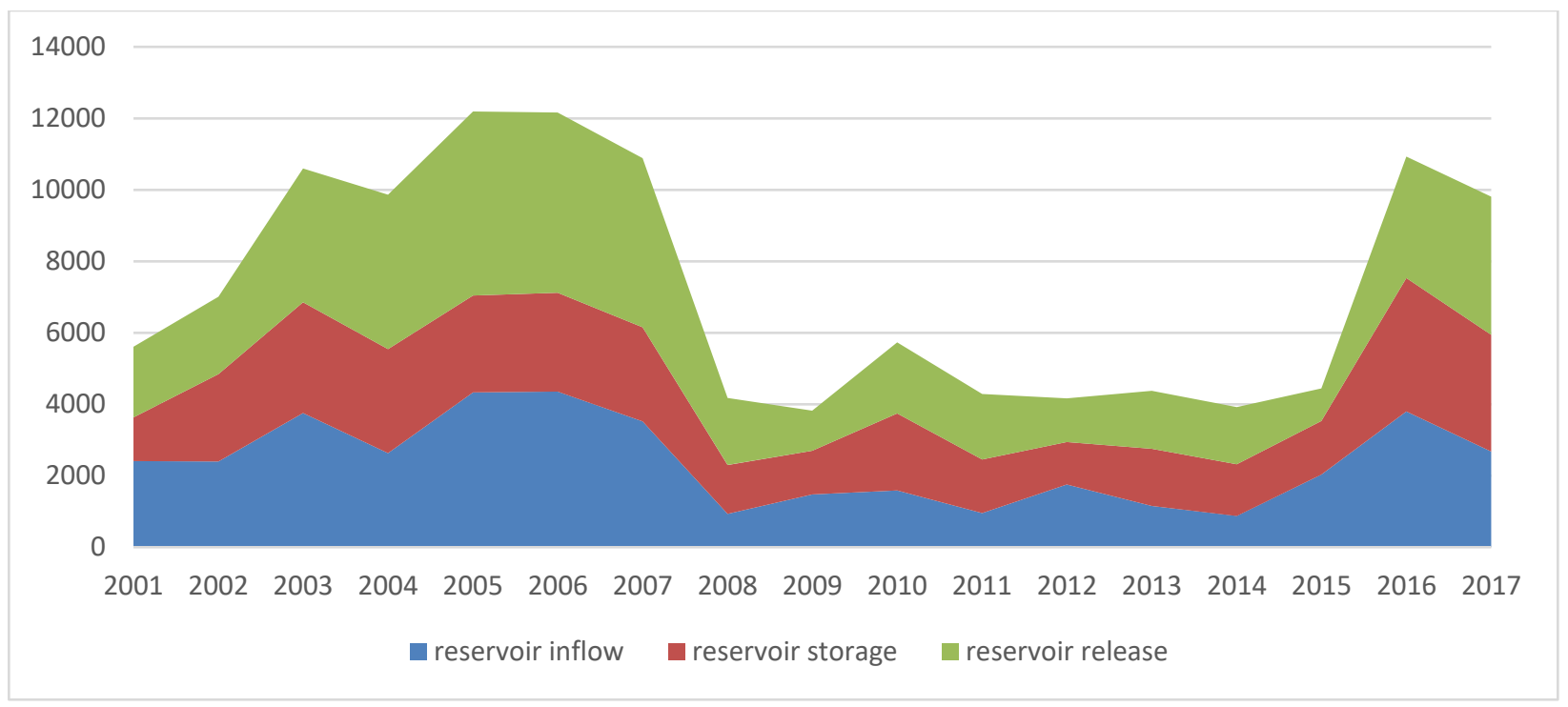

Fig. 4 - The trend of changes in inflow, storage and release volume of the reservoir from 2001 to 2017

According to the data used, the membership functions of the fuzzy inference system were defined for the input and output variables, including five Gaussian membership functions and seven linear membership functions, respectively, for different months . For instance, Fig. 5 shows the Gaussian membership functions of the April input variables.

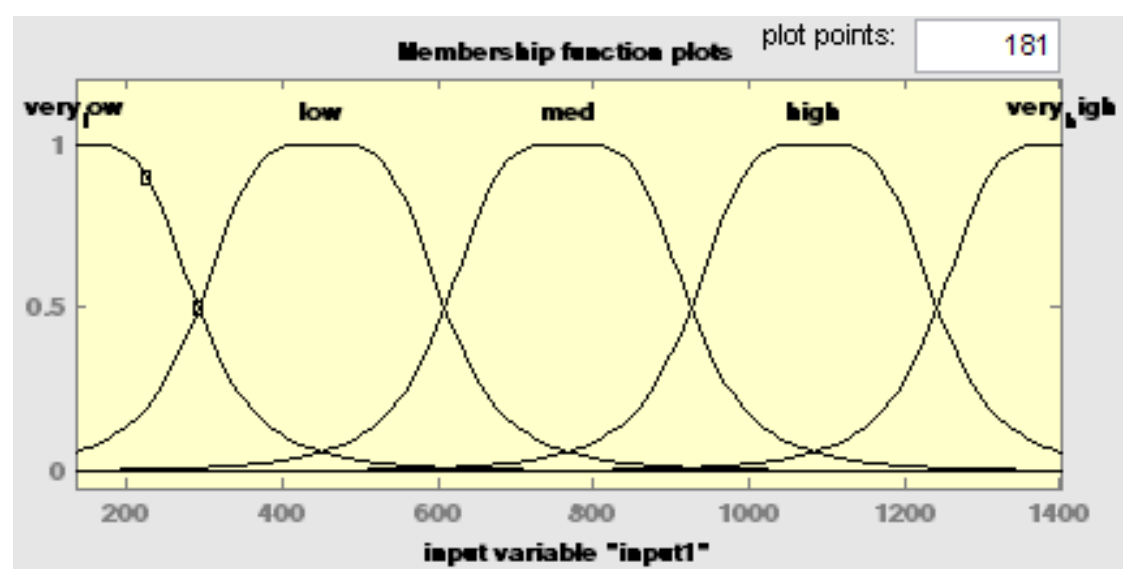




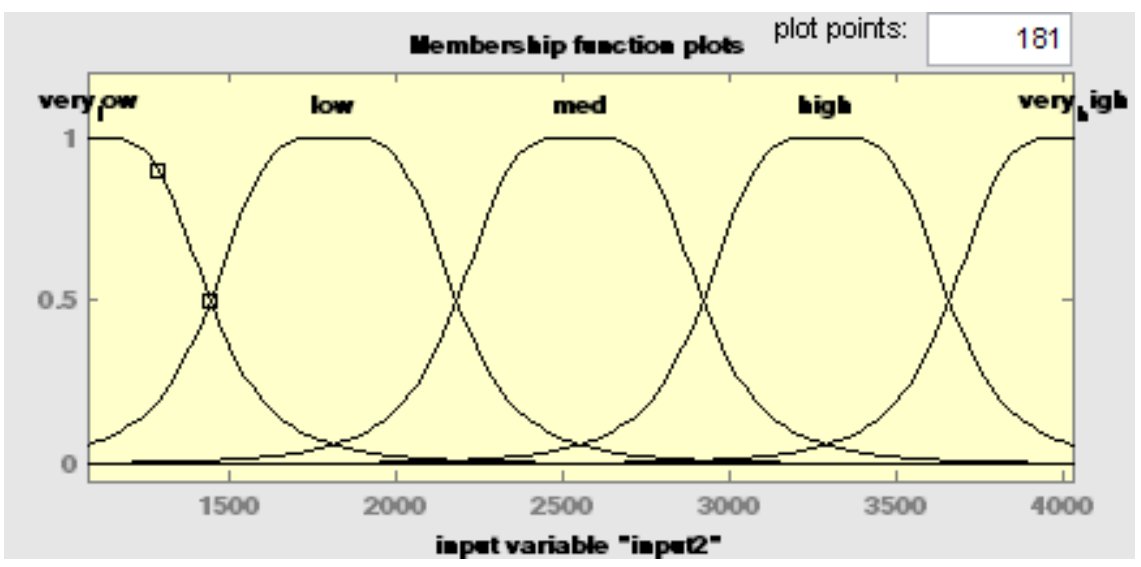

Fig. 5- Membership functions of ANFIS model input variables

The maximum and minimum data of the variables were considered as the upper and lower bounds of the membership functions. Therefore, for input variables including inflow and storage volume from the reservoir, five Gaussian membership functions included "Very Low", "Low", "Medium", "High", and "Very High", and for the output variable (release volume), seven linear membership functions including "Very Low", "Low", "Relatively Low", "Medium", "Relatively High", "High", and "Very High" were considered. Also, the Center of Gravity (COG) and Equal Frequency Discretization (EFD) methods were used for the defuzzification and classification of the mentioned functions, respectively (Yang and Web, 2009; Jiang et al., 2009).

The best combination of the reservoir operation rules was obtained based on the minimum mean square error in the training and test parts for each month. Next, the three-dimensional solution space was obtained according to the extraction rules of reservoir operation for different months. Fig. 6 shows an example of this space for the months of June, September, December, and March. 

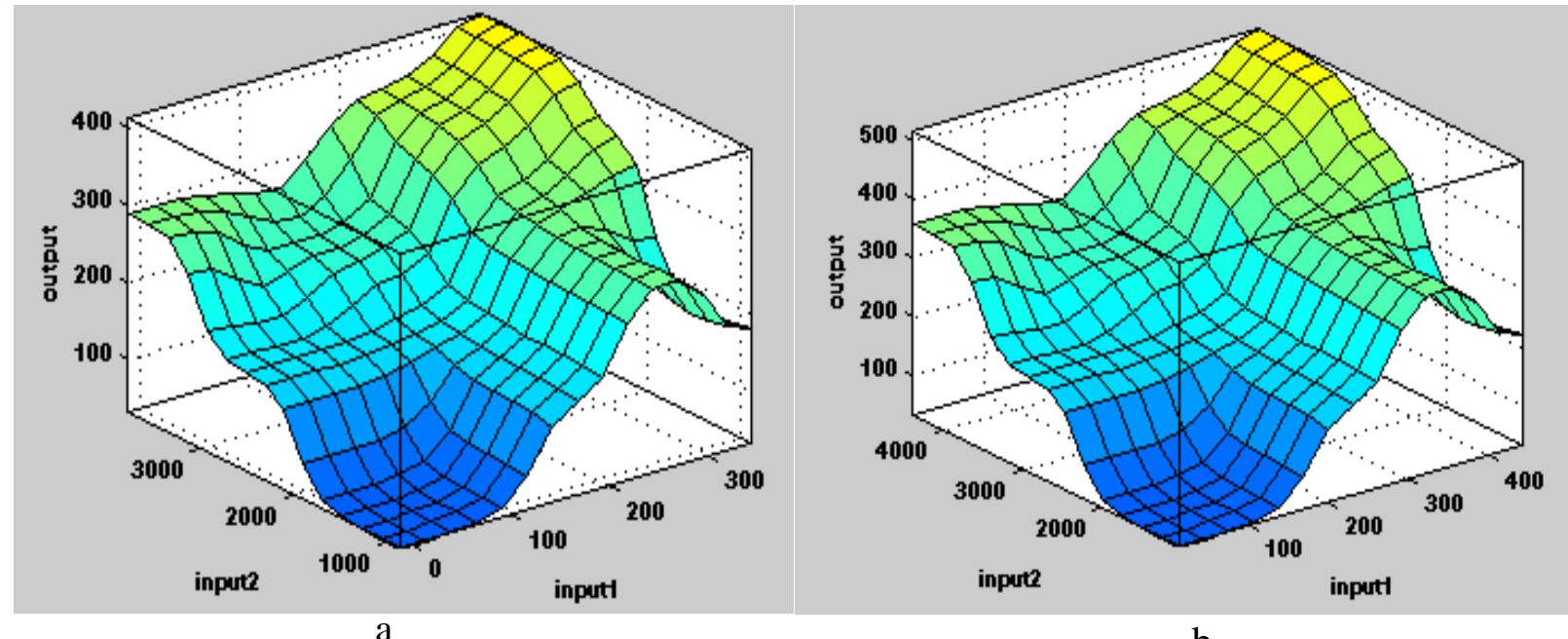

b

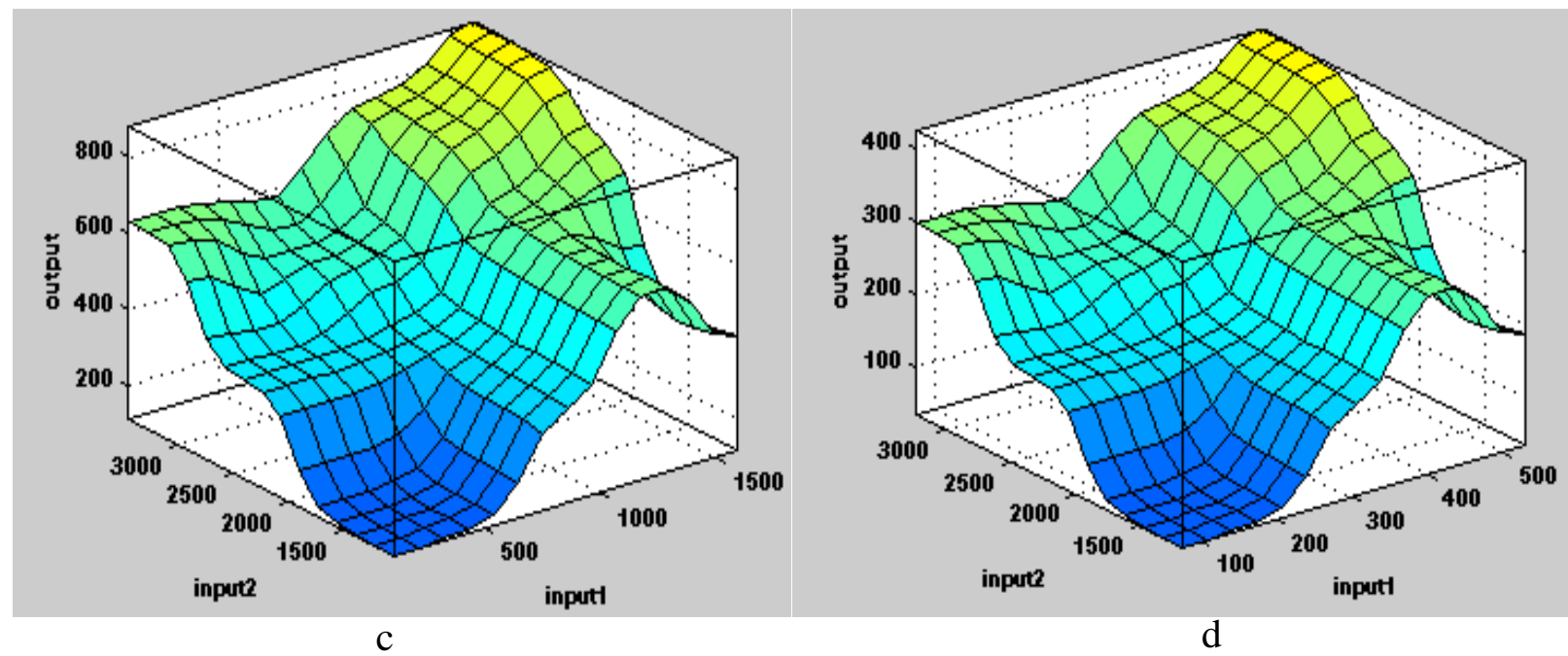

Fig. 6- ANFIS model three-dimensional solution space, a: June, b: September, c: December and

\section{d: March}

Finally, according to the obtained solution space, the amount of water released from the reservoir was simulated (predicted) separately for different months. After that, the amount of observed and simulated annual release water was obtained from the sum of these values in different months of each year (Fig. 7). According to the results, the percentage of change in the predicted released water volume based on the rules of proper operation compared to the observed values was about $14.8 \%$. The results showed that the predicted volume for water release in most years, except 2002, 
2016, and 2017, was less than the observed volume. Also, the analysis of input variable data showed that the inflow to the reservoir and the reservoir storage volume were high during 2002, 2016, and 2017. Therefore, it can be concluded that more water can be released in wet years. In dry years, however, the volume of released water obtained through ANFIS method was less than the observed values, proving that the water supply was not properly managed in drought conditions. The reason for this could be meet the water requirements for agriculture and wetlands downstream of the dam.

The results obtained from ANFIS method had a high validity owing to the effective input variables, logical and appropriate operation rules, application of uncertainty conditions, and the use of neural network methods in predicting the output variable, which has been proven in other studies (Khadr et al., 2014; Yaseen et al., 2017 Ashrafi et al., 2017).

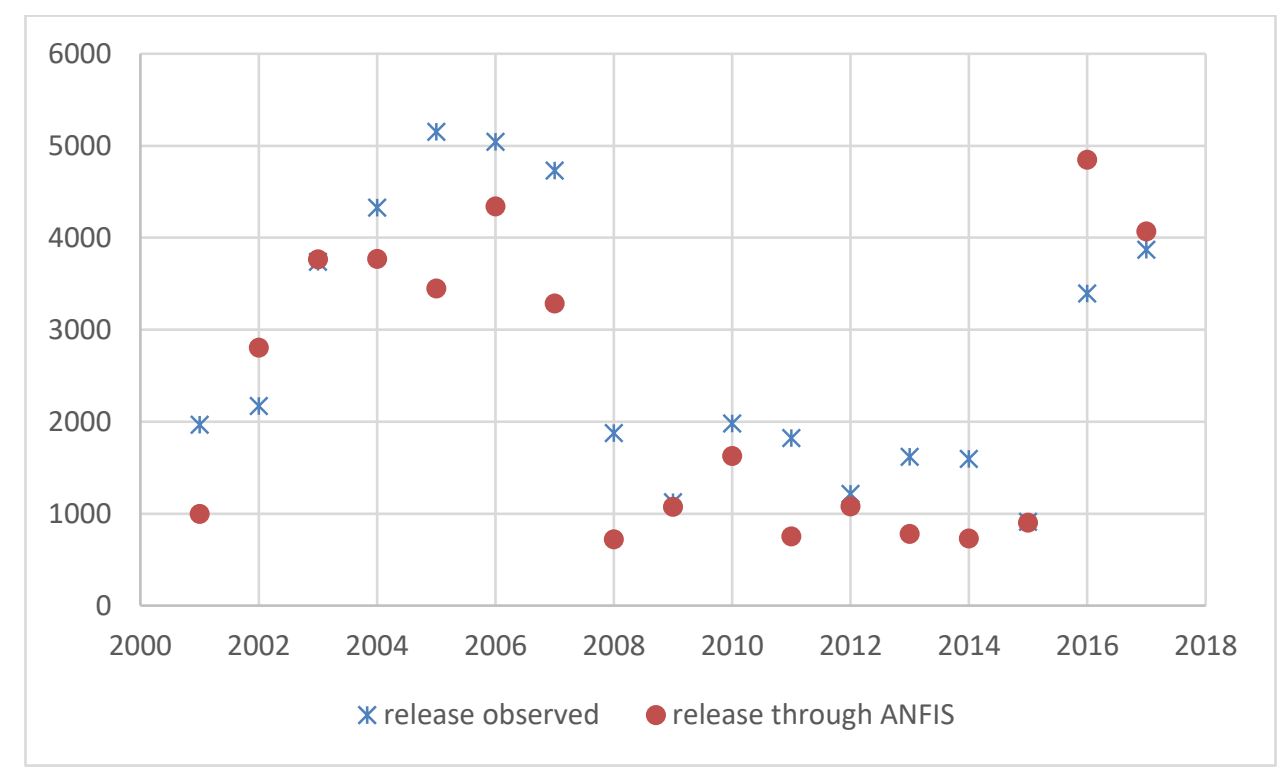

Fig. 7- Comparison of observed and predicted release water volume

In order to manage the demand for irrigation water in the southern Karkheh basin, which includes the agricultural regions of Payepol, Kowsar-Quds, Hamidiyeh, Azadegan, and Karkheh Noor in 
Khuzestan province, an optimal cropping pattern model was extracted with the aim of maximizing the gross profit and minimizing the farmers' water consumption .

The irrigation schedule of cultivated crops for different months of the year is presented in Table 1, which shows crops such as wheat, barley, canola, tomatoes, onions, and sugar beets were grown in autumn and winter. Furthermore, crops such as mung bean, cucumber, watermelon, corn, rice, sesame, and beans were grown in spring and summer .

Table 1- Growth period and irrigation schedule of arable crops in the study area

\begin{tabular}{|c|c|c|c|c|c|c|c|c|c|c|c|c|}
\hline Crops & Jan & Feb & Mar & Apr & May & Jun & Jul & Aug & Sep & Oct & Nov & Dec \\
\hline \multicolumn{13}{|l|}{ Wheat } \\
\hline \multicolumn{13}{|l|}{ Barley } \\
\hline \multicolumn{13}{|c|}{ Rapeseed } \\
\hline \multicolumn{13}{|l|}{ Tomato } \\
\hline \multicolumn{13}{|l|}{ Onion } \\
\hline \multicolumn{13}{|c|}{ Sugar beet } \\
\hline \multicolumn{13}{|c|}{ Mung bean } \\
\hline \multicolumn{13}{|c|}{ Cucumber } \\
\hline \multicolumn{13}{|c|}{ Watermelon } \\
\hline \multicolumn{13}{|l|}{ Maize } \\
\hline \multicolumn{13}{|l|}{ Rice } \\
\hline \multicolumn{13}{|l|}{ Sesame } \\
\hline Bean & & & & & & & & & & & & \\
\hline
\end{tabular}

Fig. 8 shows that in 2017, the amount of predicted release water in spring, especially in April, was much higher than the observed release water. The reason for this finding was the amount of heavy rainfall in the spring, followed by the high rate of input flow and reservoir storage variables . 
Given the water consumption of these areas compared to the water released from Kowsar Dam in 2017, about 30\% of the monthly released water in this year, predicted via ANFIS and the use of appropriate operation rules, was considered as available water (Fig. 8).

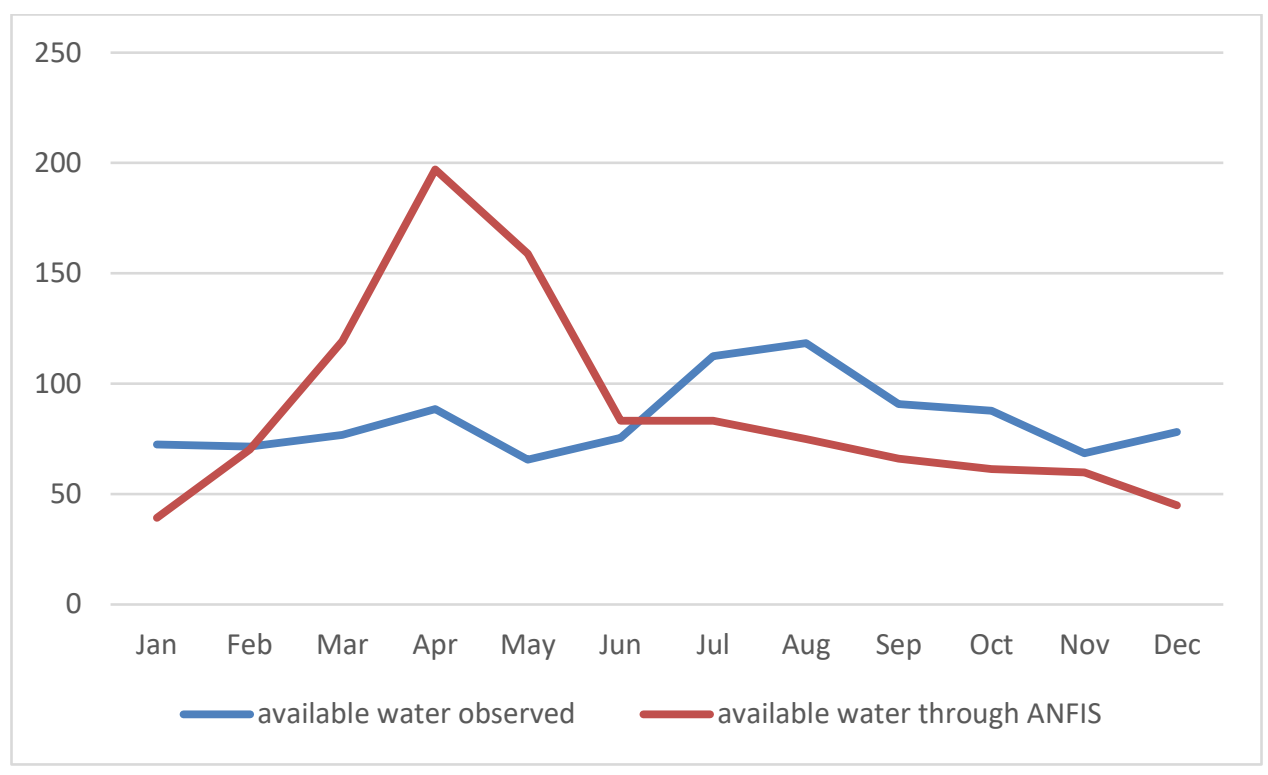

Fig. 8- Comparison of the amount of available water observed and predicted through ANFIS for the South Karkheh sub-basin

The two-objective model introduced according to the 2017 data was solved through the augmented $\varepsilon$-constraint method and the Payoff matrix for the basin was extracted (Table 2). The elements of each row of this matrix were determined through optimizing the respective objective regardless of the other. Therefore, there is an optimal objective in each row and the value of the other is calculated parametrically .

The results of the payoff matrix showed that the maximum gross profit, regardless of the other objective, was equal to $\$ 1667.06$, in which case, the amount of water consumption would be 14733.27 cubic meters per hectare. On the other hand, the minimum amount of water consumption, regardless of the other objective, was equal to 7555.59 cubic meters per hectare, in which case, the 
profit rate would be $\$ 404.09$ per hectare. Therefore, the results of the payoff matrix clearly demonstrate the contrast between the studied objectives. Afterwards, using the TOPSIS method and with the same weight of objectives, the best answer was obtained from the set of efficient solutions (Fig. 9). The results showed that the optimal amount of gross profit and water consumption in the basin was equivalent to $\$ 1554$ and 13323 cubic meters per hectare, respectively .

Table 2 - Payoff matrix results

\begin{tabular}{ccc}
\hline Payoff matrix & Gross margin (Dollar per hectares) & Water consumption (m3 per hectares) \\
\hline Maximization of gross margin & 1667.06 & 14733.27 \\
Minimization of water consumption & 404.09 & 7555.59 \\
\hline
\end{tabular}

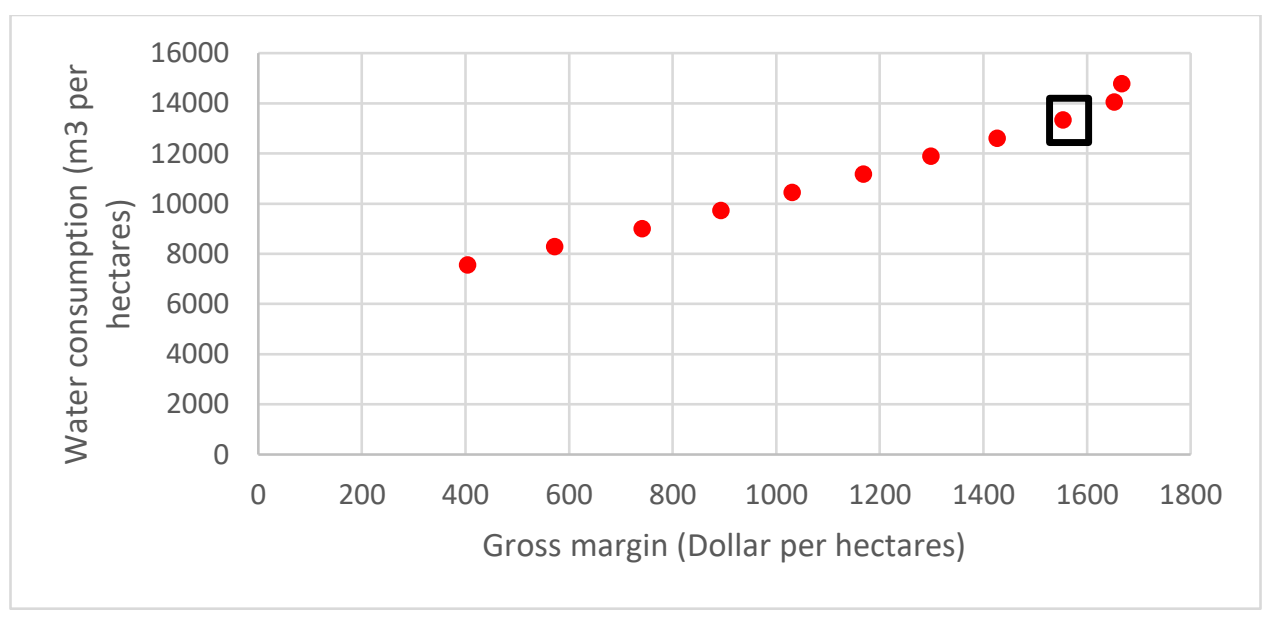

Fig. 9- Total efficient solutions of multi-objective planning model and the best answer obtained from TOPSIS method

Table 3 reports the optimal cropping pattern to achieve the best solution of objectives by regions. It is observed that the total area under cultivation of all regions in optimal conditions decreased compared to the existing cropping pattern (base). This finding is supported by the findings of 
Mardani Najafabadi et al. (2019). Hamidiyeh and Karkheh Noor regions (-70\%) had the highest and Azadegan (-19\%) and Kowsar-Quds (-18\%) had the lowest reduction in cultivation area . The optimal gross profit of Kowsar-Quds and Azadegan regions more than doubled compared to the basic conditions. Meanwhile, this parameter decreased by $70 \%$ in Hamidiyeh and Karkheh Noor regions. Water consumption of all regions decreased in the optimal pattern due to the reduction in cultivated areas. As a result, the most severe decrease in this parameter was about $70 \%$ and related to Hamidiyeh and Karkheh Noor regions .

Based on the results of Table (3), by implementing the optimal cropping pattern in the regions of Payepol, Kowsar-Quds, and Azadegan, water economic efficiency can be significantly improved. The composition of cultivation in different regions showed that this increase was due to the change in cropping patterns from low gross profit crops (wheat) to high gross profit crops (onion and watermelon). Accordingly, in Payepol region, about $46 \%$ of the total optimal cropping pattern in this region was allocated to onion cultivation, while in the basic conditions, this crop was not cultivated in this area.

In Kowsar-Quds region, watermelon had similar conditions and a large share of the optimal cropping pattern (about 64\%) was related to this crop. Onion and watermelon were also included in the optimal cropping pattern of Azadegan region, and in total they comprised about $63 \%$ of the cultivated area. Different results for different regions indicate the dynamic and multilevel nature of changes in available water resources in terms of vulnerability and adaptation, which has been proven in other studies (Westerhoff \& Smit, 2008; Reidsma et al., 2010; Esteve et al., 2015; Mirzaei and Zibaei, 2021).

Table 3- Optimal and basic cropping pattern of different regions

$\begin{array}{llll}\text { Payepol Kosar-Ghods } & \text { Hamidiyeh } & \text { Azadegan } & \text { Karkheh Noor }\end{array}$




\begin{tabular}{|c|c|c|c|c|c|c|c|c|c|c|}
\hline & $\begin{array}{c}\text { Optimal } \\
(\%)\end{array}$ & $\begin{array}{c}\text { Base } \\
(\%)\end{array}$ & $\begin{array}{c}\text { Optimal } \\
(\%)\end{array}$ & $\begin{array}{c}\text { Base } \\
(\%)\end{array}$ & $\begin{array}{c}\text { Optimal } \\
(\%)\end{array}$ & $\begin{array}{c}\text { Base } \\
(\%)\end{array}$ & $\begin{array}{c}\text { Optimal } \\
(\%)\end{array}$ & $\begin{array}{c}\text { Base } \\
(\%)\end{array}$ & $\begin{array}{c}\text { Optimal } \\
(\%)\end{array}$ & $\begin{array}{c}\text { Base } \\
(\%)\end{array}$ \\
\hline Wheat & 31 & 57 & 24 & 67 & 69 & 69 & 27 & 73 & 67 & 67 \\
\hline Barley & 8 & 14 & 2 & 5 & 3 & 3 & 4 & 12 & 17 & 17 \\
\hline Rapeseed & 0 & 0 & 0 & 1 & 0 & 0 & 0 & 0 & 0 & 0 \\
\hline Tomato & 2 & 3 & 2 & 6 & 1 & 1 & 0 & 0 & 0 & 0 \\
\hline Onion & 46 & 0 & 0 & 0 & 0 & 0 & 26 & 0 & 0 & 0 \\
\hline Sugar beet & 1 & 1 & 0 & 0 & 0 & 0 & 0 & 0 & 0 & 0 \\
\hline Mung bean & 1 & 2 & 0 & 0 & 0 & 0 & 0 & 0 & 0 & 0 \\
\hline Cucumber & 0 & 0 & 0 & 1 & 1 & 1 & 0 & 0 & 0 & 0 \\
\hline Watermelon & 2 & 5 & 64 & 0 & 0 & 0 & 37 & 1 & 0 & 0 \\
\hline Maize & 7 & 12 & 0 & 0 & 0 & 0 & 0 & 0 & 0 & 0 \\
\hline Rice & 1 & 3 & 7 & 19 & 25 & 25 & 5 & 14 & 13 & 13 \\
\hline Sesame & 1 & 2 & 0 & 0 & 1 & 1 & 0 & 0 & 1 & 1 \\
\hline Bean & 0 & 0 & 0 & 1 & 0 & 0 & 0 & 0 & 1 & 1 \\
\hline $\begin{array}{l}\text { Aggregate } \\
\text { (hectares) }\end{array}$ & $\begin{array}{c}12965.2 \\
(\%-44)\end{array}$ & 23178 & $\begin{array}{l}10866 \\
(\%-18)\end{array}$ & 13200 & $\begin{array}{l}4225.5 \\
(\%-70)\end{array}$ & 14085 & $\begin{array}{l}18096 \\
(\%-19)\end{array}$ & 22367 & $\begin{array}{l}6878.4 \\
(\%-70)\end{array}$ & 22928 \\
\hline $\begin{array}{c}\text { Gross margin } \\
\text { (thousand } \\
\text { dollar) }\end{array}$ & $\begin{array}{l}16919.8 \\
(\%-0.5)\end{array}$ & 17012.7 & $\begin{array}{l}23530.7 \\
(\% 114)\end{array}$ & 11004.3 & $\begin{array}{l}3417.2 \\
(\%-70)\end{array}$ & 11390.6 & $\begin{array}{l}33937.6 \\
(\% 103)\end{array}$ & 16683.1 & $\begin{array}{l}4601.9 \\
(\%-70)\end{array}$ & 15339.5 \\
\hline $\begin{array}{c}\text { Water } \\
\text { consumption } \\
(\mathrm{MCM})\end{array}$ & $\begin{array}{l}143.201 \\
(\%-50)\end{array}$ & 288.522 & $\begin{array}{l}159.929 \\
(\%-10)\end{array}$ & 178.587 & $\begin{array}{l}69.344 \\
(\%-70)\end{array}$ & 231.147 & $\begin{array}{l}227.852 \\
(\%-19)\end{array}$ & 282.110 & $\begin{array}{c}106.565 \\
(\%-70)\end{array}$ & 355.218 \\
\hline $\begin{array}{c}\text { Water } \\
\text { economic } \\
\text { productivity } \\
\text { (dollar per } \\
\text { m3) }\end{array}$ & $\begin{array}{c}0.118 \\
(\% 100)\end{array}$ & 0.059 & $\begin{array}{c}0.147 \\
(\% 137)\end{array}$ & 0.062 & $\begin{array}{l}0.049 \\
(\% 0)\end{array}$ & 0.049 & $\begin{array}{c}0.149 \\
(\% 153)\end{array}$ & 0.059 & $\begin{array}{l}0.043 \\
(\% 0)\end{array}$ & 0.043 \\
\hline
\end{tabular}


Fig. 10 compares the total cultivation of different crops, gross profit, water consumption, and economic efficiency of water in the whole basin area under optimal and basic conditions. As observed, in order to achieve economic and environmental objectives in the whole area of the basin, according to the amount of water available from the ANFIS method, it is necessary to reduce wheat cultivation by about $30 \%$ and increase onion and watermelon cultivation instead. These changes at the basin level will increase the total gross profit by more than $\$ 10$ million, reduce water consumption by more than 600 million cubic meters, and increase water economic efficiency from $\$ 0.06$ to $\$ 0.12$.

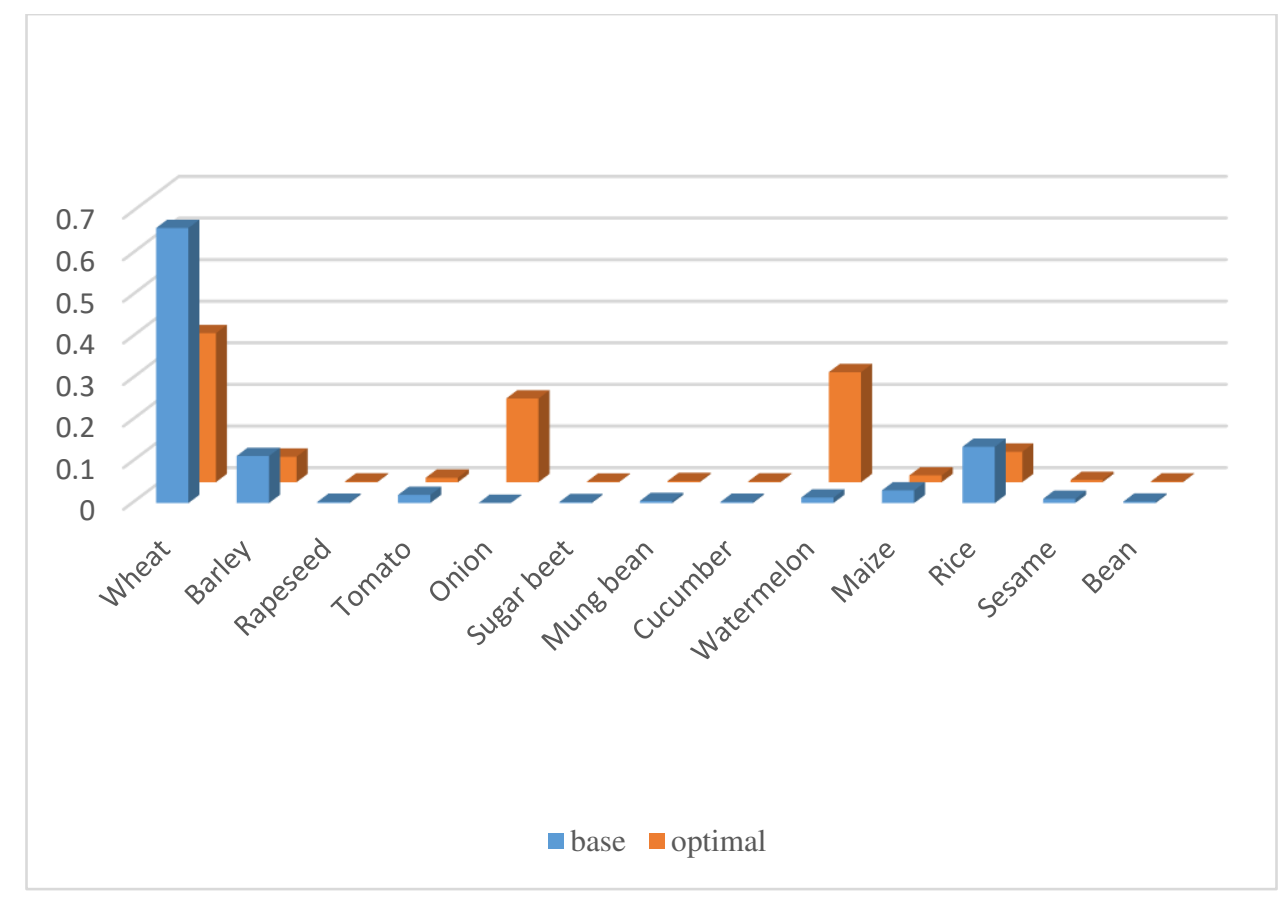



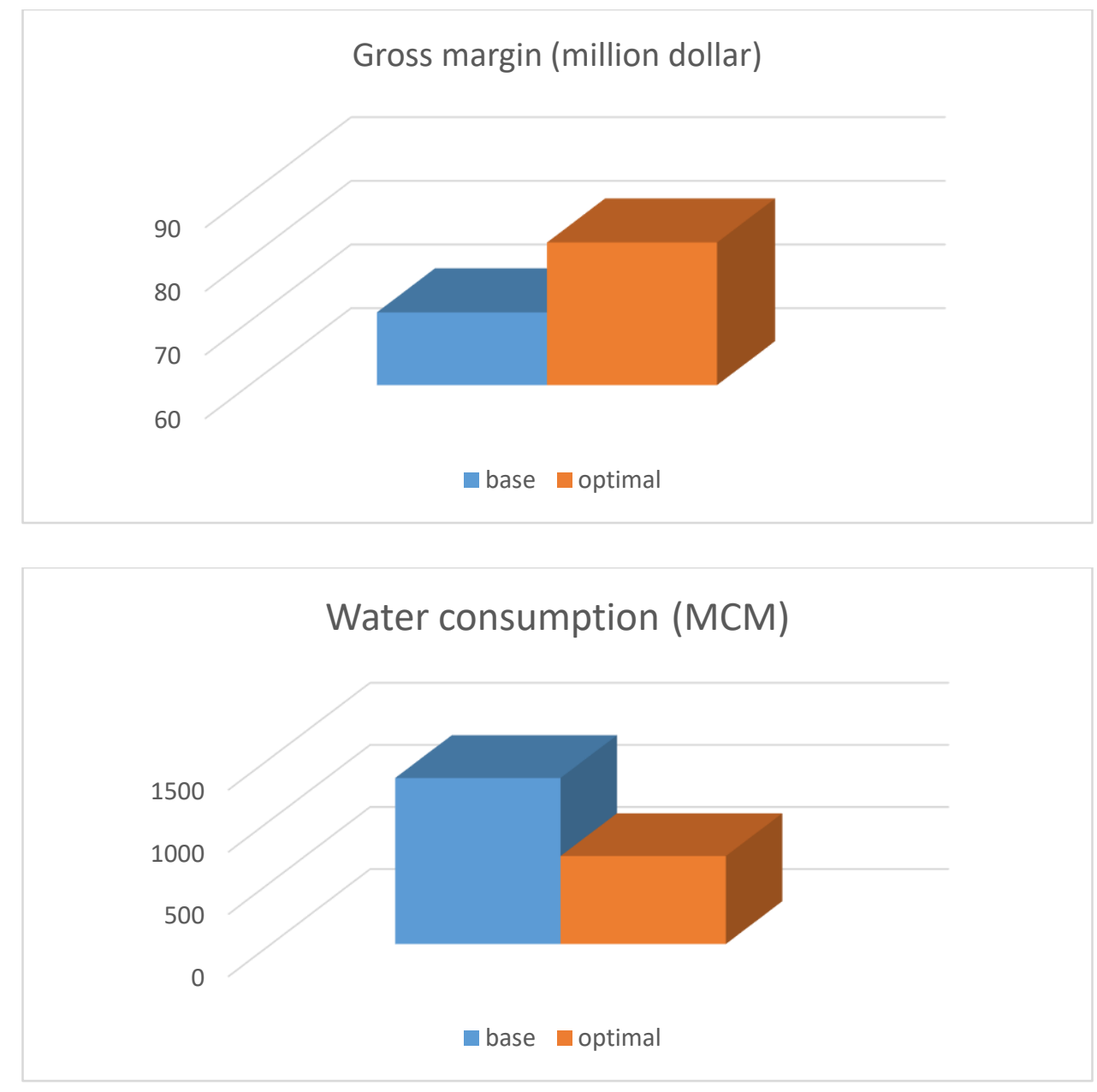

Water economic productivity (dollar per m3)

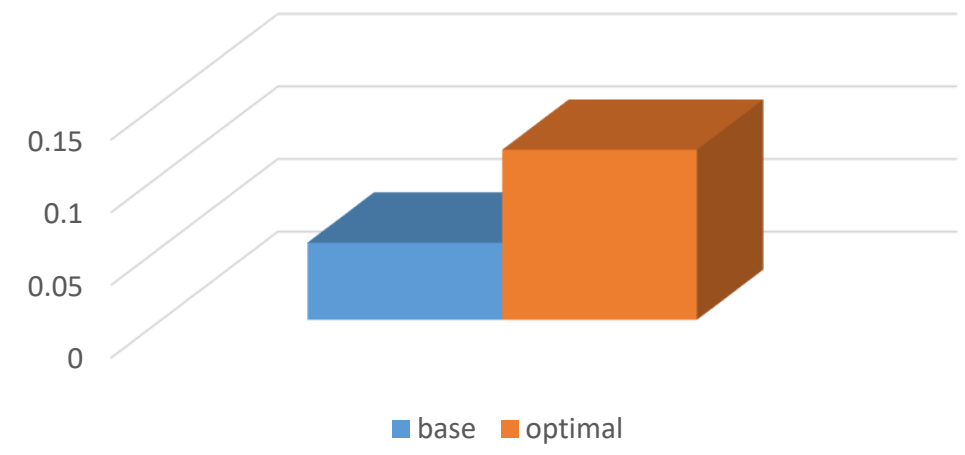

Fig. 10- Comparison of crop cultivation area, gross profit, water consumption and economic efficiency of water in basic and optimal models 
The model used in the current study was able to improve the farmers' profit, reduce water consumption, and significantly increase water economic productivity by optimal water supply and demand management and providing a suitable cropping pattern. Comparison of the results of this study with others (for example Garg et al., 2014; Galan-Martína et al., 2015; Esteve et al., 2015; Zhang \& Guo, 2016; Mardani Najafabadi et al., 2019; Mirzaei and Zibaei, 2021), shows that so far, the various planning models in different basins have not been able to achieve such an improvement in water economic efficiency .

On the other hand, contrary to popular belief, the adoption of some of these strategies, while improving hydrological performance, can also increase the gross margin of farmers. Therefore, increasing farmers' profit is possible while reducing their water consumption, which has been corroborated by other studies (Tanaka et al., 2006; Esteve et al., 2015; Mirzaei and Zibaei, 2021).

\section{Conclusion}

The purpose of this study was to provide a framework for simultaneous management of water supply and demand with economic and environmental objectives under uncertainty. For this purpose, the southern Karkheh basin of Khuzestan province was selected as a case study. Operation rules of Karkheh dam were extracted as a water supplier under the southern Karkheh basin and the volume of water released from the reservoir was estimated using the ANFIS model. Then, using the multi-objective programming model and applying the augmented $\varepsilon$-constraint method, the available water resources were allocated to different agricultural areas in the basin . According to the results, the use of proper operation rules and the ANFIS model were able to manage water release in different months of the year according to inflows and reservoir storage volume. Thus, in wet years more water volume and in drought years less water volume was 
released. Therefore, because the rate of release from the reservoir of Karkheh Dam is not optimal in the current situation, it is recommended that water resources planners and policy makers use the proposed model to decide on the release of water from this dam.

From the results of the study, it can be seen that reducing the total area under cultivation and modifying the cropping pattern to increase onion and watermelon cultivation plays an effective role in managing water demand for the study areas. The proposed conceptual framework was able to increase the gross profit, reduce farmers' water consumption to meet the environmental needs of the basin, and improve the economic efficiency of water.

Finally, it is suggested that according to the capabilities of the current model for comprehensive management of water resources, this model should be used to create an initiative for the relevant managers of other basins in Iran .

\section{Authors Contributions}

The first and second authors conceived of the presented idea and developed the theory and performed the computations. The third and fourth authors verified the analytical methods. All authors discussed the results and contributed to the final manuscript.

\section{Funding}

Not applicable

\section{Compliance with ethical standards}

The authors state that they have no conflict of interest. 


\section{Availability of data and materials}

Data and model estimation output are available from the corresponding author upon reasonable request.

\section{References}

1. Allan, J. A. (2003). Integrated water resources management is more a political than a technical challenge. Development Water Science, 50, 9-23.

2. Allawi, M. F., Jaafar, O., Hamzah, F. M., \& El-Shafie, A. (2019). Novel reservoir system simulation procedure for gap minimization between water supply and demand. Journal of Cleaner Production, 206, 928-943.

3. Ashrafi, M., Chua, L.H.C., Quek, C., Qin, X., 2017. A fully-online Neuro-Fuzzy model for flow forecasting in basins with limited data. J. Hydrol. 545, 424-435.

4. Boazar, M., Yazdanpanah, M., \& Abdeshahi, A. (2019). Response to water crisis: How do Iranian farmers think about and intent in relation to switching from rice to less waterdependent crops?. Journal of hydrology, 570, 523-530.

5. Choubin, B., Solaimani, K., Rezanezhad, F., Roshan, M. H., Malekian, A., \& Shamshirband, S. (2019). Streamflow regionalization using a similarity approach in ungauged basins: Application of the geo-environmental signatures in the Karkheh River Basin, Iran. Catena, 182, 104128.

6. Ebtehaj, I., Bonakdari, H., 2014. Performance Evaluation of Adaptive Neural Fuzzy Inference System for Sediment Transport in Sewers. Water Resour. Manag. 28, 47654779. 
7. El-Shafie, A., Taha, M. R., \&Noureldin, A. (2007). A neuro-fuzzy model for inflow forecasting of the Nile River at Aswan high dam. Water resources management, 21(3), 533-556.

8. Enrique, S., Manuel, F., Colmenarejo, J.A., Angel, R.G., Garc, L.T. and Borja, R. 2007. Use of the water quality index and dissolved oxygen deficit as simple indicate of watershed pollution. Ecological Indicator, 7: 315-328.

9. Esmaeel Nezhad, A. E., Javadi, M. S., \& Rahimi, E. (2013). Applying augmented econstraint approach and lexicographic optimization to solve multi-objective hydrothermal generation scheduling considering the impacts of pumped-storage units. In Electrical Power and Energy Systems (Vol. 55, pp. 195-204). Elsevier.

10. Esteve, P., Varela-Ortega, C., Gutierrez, I., \& Downing, T. E. (2015). A hydro-economic model for the assessment of climate change impacts and adaptation in irrigated agriculture. Ecological Economics, 120, 49-58.

11. F. Nasirzadehroshenin, M. Sadeghzadeh, A. Khadang, H. Maddah, M.H. Ahmadi, H. Sakhaeinia, L. Chen, Modeling of heat transfer performance of carbon nanotube nanofluid in a tube with fixed wall temperature by using ANN-GA, Eur. Phys. J. Plus 135 (2) (2020) 217.

12. Fani, A., Ghazi, I., \& Malekian, A. (2016). Challenges of Water Resource Management in Iran. American Journal of Environmental Engineering, 6(4), 123-128.

13. FAO, 2015. Food and Agriculture Organization of the United Nations. http://www. fao.org/about/what-we-do/so1/en/. 
14. Fathipour, F., \& Saidi-Mehrabad, M. (2018). A multi-objective energy planning considering sustainable development by a TOPSIS-based augmented e-constraint. Journal of Renewable and Sustainable Energy, 10(3), 034901.

15. Fereidoon, M., \& Koch, M. (2018). SWAT-MODSIM-PSO optimization of multi-crop planning in the Karkheh River Basin, Iran, under the impacts of climate change. Science of The Total Environment, 630, 502-516.

16. Flach, R., Skalský, R., Folberth, C., Balkovič, J., Jantke, K., \& Schneider, U. A. (2020). Water productivity and footprint of major Brazilian rainfed crops-A spatially explicit analysis of crop management scenarios. Agricultural Water Management, 233, 105996.

17. Forni, L. G., Medellín-Azuara, J., Tansey, M., Young, C., Purkey, D., \& Howitt, R. (2016). Integrating complex economic and hydrologic planning models: An application for drought under climate change analysis. Water Resources and Economics, 16, 15-27.

18. Francisco, S.R., Mubarik, A., 2006. Resource allocation tradeoffs in Manila's peri-urban vegetable production systems: an application of multiple objective programming. Agric. Syst. 87, 147-168.

19. Galan-Martína, A., Pozo, C., Guill en-Gos albez, G., Vallejo, A.A., Esteller, L.J., 2015. Multi-stage linear programming model for optimizing cropping plan decisions under the new Common Agricultural Policy. Land Use Policy, 48 (2015), pp. 515-524

20. Gao, J., Christensen, P., Kørnøv, L., 2017. Indicators' role: how do they influence strategic environmental assessment and sustainable planning e the Chinese experience. Sci. Total Environ. 592, 60-67. 
21. Garg, N.K., Dadhich, S.M., 2014. Integrated non-linear model for optimal cropping pattern and irrigation scheduling under deficit irrigation. Agricultural Water Management. 140, 113.

22. Ghobadi, Y., Pradhan, B., Sayyad, G. A., Kabiri, K., \& Falamarzi, Y. (2015). Simulation of hydrological processes and effects of engineering projects on the Karkheh River Basin and its wetland using SWAT2009. Quaternary International, 374, 144-153.

23. Guerrero-Baena, M. D., Villanueva, A. J., Gómez-Limón, J. A., \& Glenk, K. (2019). Willingness to pay for improved irrigation water supply reliability: An approach based on probability density functions. Agricultural Water Management, 217, 11-22.

24. H. Maddah, M. Ghazvini, M.H. Ahmadi, Predicting the efficiency of $\mathrm{CuO} /$ water nanofluid in heat pipe heat exchanger using neural network, Int. Commun. Heat Mass Transf. 104 (2019) 33-40.

25. Hadiyan, P. P., Moeini, R., \& Ehsanzadeh, E. (2020). Application of static and dynamic artificial neural networks for forecasting inflow discharges, case study: Sefidroud Dam reservoir. Sustainable Computing: Informatics and Systems, 27, 100401.

26. Hadizadeh, F., Allahyari, M. S., Damalas, C. A., \& Yazdani, M. R. (2018). Integrated management of agricultural water resources among paddy farmers in northern Iran. Agricultural Water Management, 200, 19-26.

27. Haghiabi, A. H., \& Mastorakis, N. E. (2009). Water resources management in Karkheh Basin-Iran. In Proceedings of the 3rd International Conference on Energy and Development-Environment-Biomedicine (EDEB'09), Vouliagmeni, Athens, Greece December (pp. 29-31). 
28. Hwang C and Masud A, 2012. Multiple objective decision making, methods and applications: A state of the art survey. Economic and Mathematical System, 164: 18-27.

29. IPCC (the Intergovernmental Panel on Climate Change), 2014. Climate Change 2014: Impact Adaptation and Vulnerability. Summary for Policymakers. Contribution of Working Group II to the Fifth Assessment Report of the Intergovernmental Panel on Climate Change. Cambridge University Press, Cambridge and NewYork.

30. Jang, J.R. 1993. ANFIS: Adaptive Network-Based Fuzzy Inference System, Proc., IEEE Conf. Trans Syst., man Cybern, 23:665:685.

31. Jiang, Sh., Li, X., Zheng, Q. and Wang, L. 2009. Approximate equal frequency discretization method, Intelligent Systems, Global Congress, 19-21 May 2009. P: 514-518.

32. Kambalimath, S., \& Deka, P. C. (2020). A basic review of fuzzy logic applications in hydrology and water resources. Applied Water Science, 10(8), 1-14.

33. Karimi, A. and Ardakanian, R., 2010. Development of a Dynamic Long-Term Water Allocation Model for agriculture and industry water deman. Wat.Resour. Manage., 24:1717-1746.

34. Khadr, M. and A. Schlenkhoff, Integration of Data-Driven Modeling and Stochastic Modeling for Multi-purpose Reservoir Simulation, ICHE 2014. 2014, Bundesanstalt für Wasserbau: Hamburg - Lehfeldt \& Kopmann. 91-99.

35. La Jeunesse, I., Cirelli, C., Aubin, D., Larrue, C., Sellami, H., Afifi, S., ... \& Dettori, M. (2016). Is climate change a threat for water uses in the Mediterranean region? Results from a survey at local scale. Science of the Total Environment, 543, 981-996.

36. Lavee, D., 2010. The effect of water supply uncertainty on farmers' choice of crop portfolio. Agric. Water Manag. 97, 1847-1854. 
37. M. Farzaneh-Gord, B. Mohseni-Gharyehsafa, A. Arabkoohsar, M.H. Ahmadi, M.A. Sheremet, Precise prediction of biogas thermodynamic properties by using ANN algorithm, Renew. Energy 147 (2020) 179-191.

38. M. Zamen, A. Baghban, S.M. Pourkiaei, M.H. Ahmadi, Optimization methods using artificial intelligence algorithms to estimate thermal efficiency of PV/T system, Energy Sci. Eng. 7 (3) (2019) 821-834.

39. Madani, K. (2014). Water management in Iran: what is causing the looming crisis. Journal of Environmental Studies and Sciences, 4(4), 315-328.

40. Madani, K., AghaKouchak, A., \& Mirchi, A. (2016). Iran's socio-economic drought: challenges of a water-bankrupt nation. Iranian studies, 49(6), 997-1016.

41. Mardani Najafabadi, M. M., Ziaee, S., Nikouei, A., \& Borazjani, M. A. (2019). Mathematical programming model (MMP) for optimization of regional cropping patterns decisions: A case study. Agricultural Systems, 173, 218-232.

42. Marjanizadeh, S., de Fraiture, C., \& Loiskandl, W. (2010). Food and water scenarios for the Karkheh River Basin, Iran. Water International, 35(4), 409-424.

43. Marler, R. T., \& Arora, J. S. (2004). Survey of multi-objective optimization methods for engineering. Structural and multidisciplinary optimization, 26(6), 369-395.

44. Masih, I., Uhlenbrook, S., Maskey, S., \& Ahmad, M. D. (2010). Regionalization of a conceptual rainfall-runoff model based on similarity of the flow duration curve: A case study from the semi-arid Karkheh basin, Iran. Journal of hydrology, 391(1-2), 188-201.

45. Mavrotas, G. (2009). Effective implementation of e-constraint method in multi-objective mathematical programming problems. Applied Mathematics and Computation, 213, 455465. 
46. Mehta, R. and Jain, S.K. 2009. Optimal operation of a multi-purpose reservoir using neurofuzzy technique, Wat. Resou. Manage., 23: 509-529.

47. Mirzaei, A., \& Zibaei, M. (2020). Water Conflict Management between Agriculture and Wetland under Climate Change: Application of Economic-Hydrological-Behavioral Modelling. Water Resources Management, 1-21.

48. Mishra, A.K., Kumar, B., Dutta, J., 2016. Prediction of hydraulic conductivity of soil bentonite mixture using Hybrid-ANN approach. J. Environ. Inf. 27 (2), 98e105.

49. Mousavi, S.J., Ponnambalam, K., and Karray, F. 2007. Inferring operating rules for reservoir operations using fuzzy regression and ANFIS,Fuzz. Set. Sysemt., 158: 10641082.

50. Nikouei, A., Zibaei, M., \& Ward, F. A. (2012). Incentives to adopt irrigation water saving measures for wetlands preservation: an integrated basin scale analysis. Journal of hydrology, 464, 216-232.

51. Niu, G., Li, Y. P., Huang, G. H., Liu, J., \& Fan, Y. R. (2016). Crop planning and water resource allocation for sustainable development of an irrigation region in China under multiple uncertainties. Agricultural Water Management, 166, 53-69.

52. P. Coulibaly, F. Anctil, B. Bobee, Daily reservoir inflow forecasting using artificial neural networks with stopped training approach, J. Hydrol. (Amst) 230 (3) (2000) 244-257.

53. Pakdel, M. J. V., Sohrabi, F., \& Mohammadi-Ivatloo, B. (2020). Multi-objective optimization of energy and water management in networked hubs considering transactive energy. Journal of Cleaner Production, 121936. 
54. Qiu, H., Chen, L., Zhou, J., He, Z., \& Zhang, H. (2020). Risk analysis of water supplyhydropower generation-environment nexus in the cascade reservoir operation. Journal of Cleaner Production, 124239.

55. Reidsma, P., Ewert, F., Lansink, A. O., \& Leemans, R. (2010). Adaptation to climate change and climate variability in European agriculture: the importance of farm level responses. The European Journal of Agronomy, 32, 91-102.

56. Ranković, V., Grujović, N., Divac, D., Milivojević, N., \& Novaković, A. (2012). Modelling of dam behaviour based on neuro-fuzzy identification. Engineering Structures, $35,107-113$.

57. Sedeño-Díaz, J. E., \& López-López, E. (2016). Fuzzy Logic as a Tool for the Assessment of Water Quality for Reservoirs: A Regional Perspective (Lerma River Basin, Mexico). Lake Sciences and Climate Change, 5, 155.

58. Sisto, N. P. (2009). Environmental flows for rivers and economic compensation for irrigators. Journal of Environmental Management, 90(2), 1236-1240.

59. Smardon, R. (2009). International wetland policy and management issues, sustaining the world's wetlands. Springer New York (pp. 1-20).

60. Smith, A., Tetzlaff, D., Gelbrecht, J., Kleine, L., \& Soulsby, C. (2020). Riparian wetland rehabilitation and beaver re-colonization impacts on hydrological processes and water quality in a lowland agricultural catchment. Science of The Total Environment, 699, 134302.

61. Soltani, F., Kerachian, R., \& Shirangi, E. (2010). Developing operating rules for reservoirs considering the water quality issues: Application of ANFIS-based surrogate models. Expert Systems with Applications, 37(9), 6639-6645. 
62. Srinivasa Prasad, A., Umamahesh, N. V., and Viswanath, G. K. 2013. Short-Term real time reservoir operation for irrigation, Journal of Water Resources Planning and Management, 139:149-158.

63. Stålnacke, P., \& Gooch, G. D. (2010). Integrated water resources management. Irrigation and Drainage Systems, 24(3-4), 155-159.

64. Steusloff, H. (Ed.). (2010). Integrated Water Resources Management Karlsruhe 2010: International Conference, 24-25 November 2010; Conference Proceedings. KIT Scientific Publishing.

65. Suryanarayana, T. M. V. and Kemkar, M. 2014. Fuzzy Rule Based Model for Optimal Reservoir Releases, Inte. J. of Moder. Engin. Res., 6:29-32.

66. Takagi, T., Sugeno, M.1983. Derivation of fuzzy control rules from human operator's control action, in Proc.IFAC Symp. Fuzzy inform., Knowledge Representation and Decision Analysis, pp. 55-60, 1983.

67. Tanaka, S. K., Zhu, T., Lund, J. R., Howitt, R. E., Jenkins, M. W., Pulido, M. A., Tauber, M., Ritzema, R. S., \& Ferreira, I. C. (2006). Climate warming and water management adaptation for California. Climate Change, 76, 361-387.

68. Tarazkar, M. H., Soltani, G. R., \& Nooshadi, M. (2018). Determining the Operating Rules Of Doroodzan Reservoir Using the Adaptive Network Fuzzy Inference System (ANFIS). JWSS-Isfahan University of Technology, 22(2), 261-276.

69. Westerhoff, L., \& Smit, B. (2008). The rains are disappointing us: dynamic vulnerability and adaptation to multiple stressors in the Afram Plains, Ghana. Mitigation Adaptation Strategies Global Change, 14, 317-337. 
70. Yang, Y. \& Web, G. I. (2009). A Comparative Study of Discretization Methods for NaiveBayes Classifiers, Mach. Learn., 74: 39-74.

71. Yaseen, Z.M., Ebtehaj, I., Bonakdari, H., Deo, R.C., Mehr, A.D., Mohtar, W.H.M.W., Diop, L., El-Shafie, A. \& Singh, V.P. (2017). Novel approach for streamflow forecasting using a hybrid ANFIS-FFA model. Journal of Hydrology, 554, 263-276.

72. Zamani, O., Grundmann, P., Libra, J. A., \& Nikouei, A. (2019). Limiting and timing water supply for agricultural production-The case of the Zayandeh-Rud River Basin, Iran. Agricultural Water Management, 222, 322-335.

73. Zargan, J., \& Waez-Mousavi, S. M. (2016). Water Crisis in Iran: Its Intensity, Causes and Confronting Strategies. Indian Journal of Science and Technology, 9(44), 1-6.

74. Zhang, D.M., Guo, P., 2016. Integrated agriculture water management optimization model for water saving potential analysis. Agricultural Water Management. 170, 5-19. 
Figures

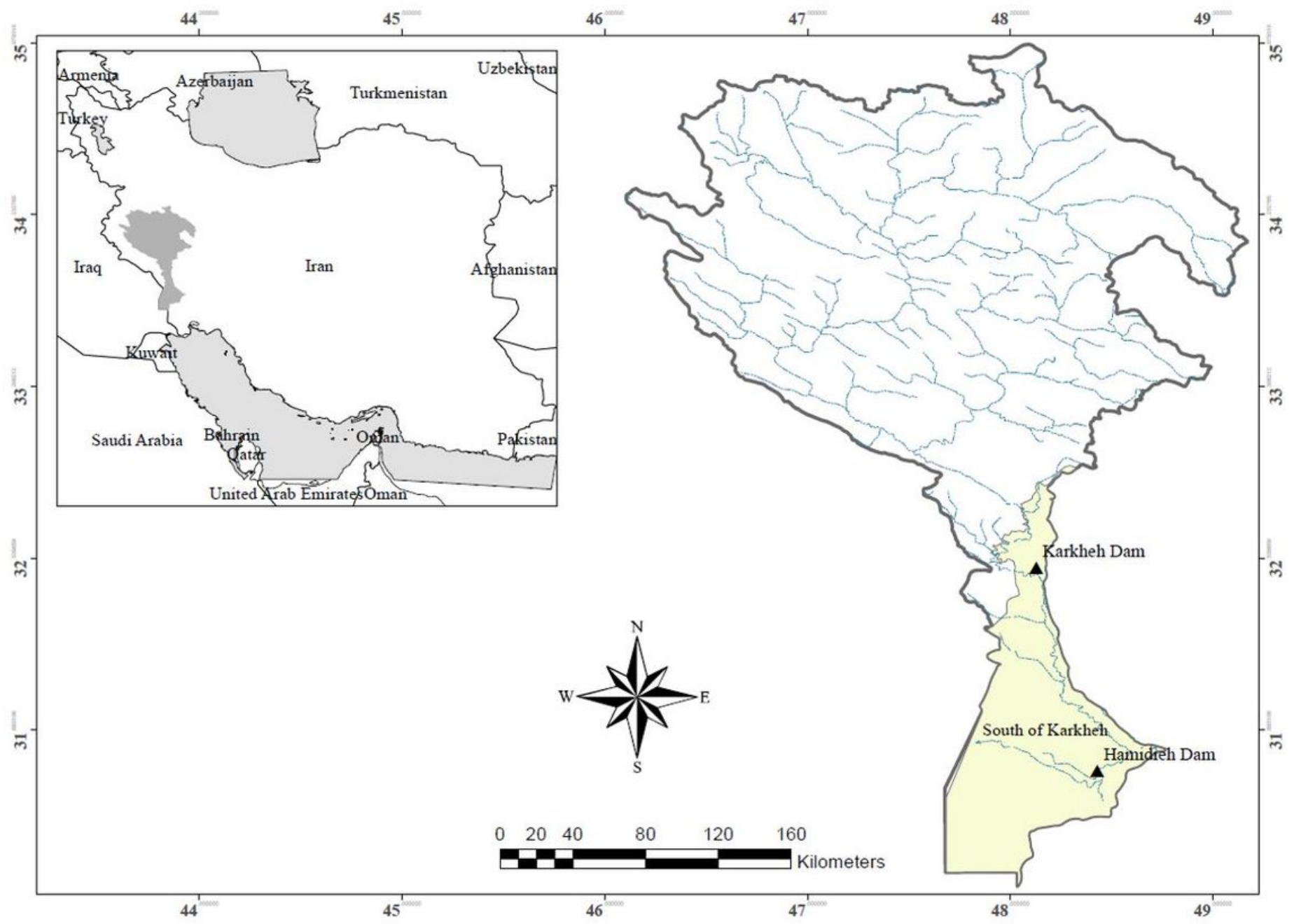

\section{Figure 1}

Location of the South Karkheh. Note: The designations employed and the presentation of the material on this map do not imply the expression of any opinion whatsoever on the part of Research Square concerning the legal status of any country, territory, city or area or of its authorities, or concerning the delimitation of its frontiers or boundaries. This map has been provided by the authors. 


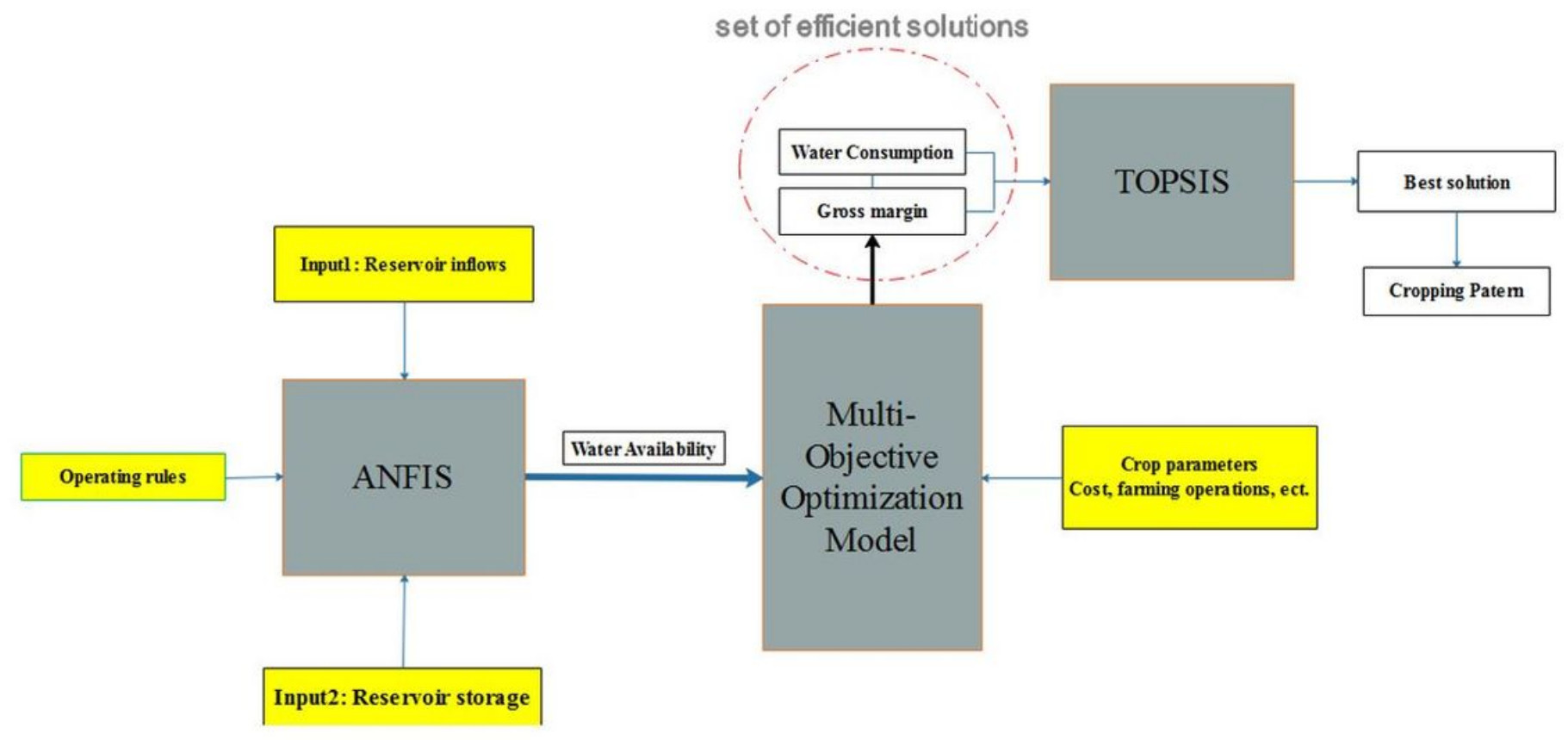

Figure 2

Conceptual framework for water resources supply and demand management

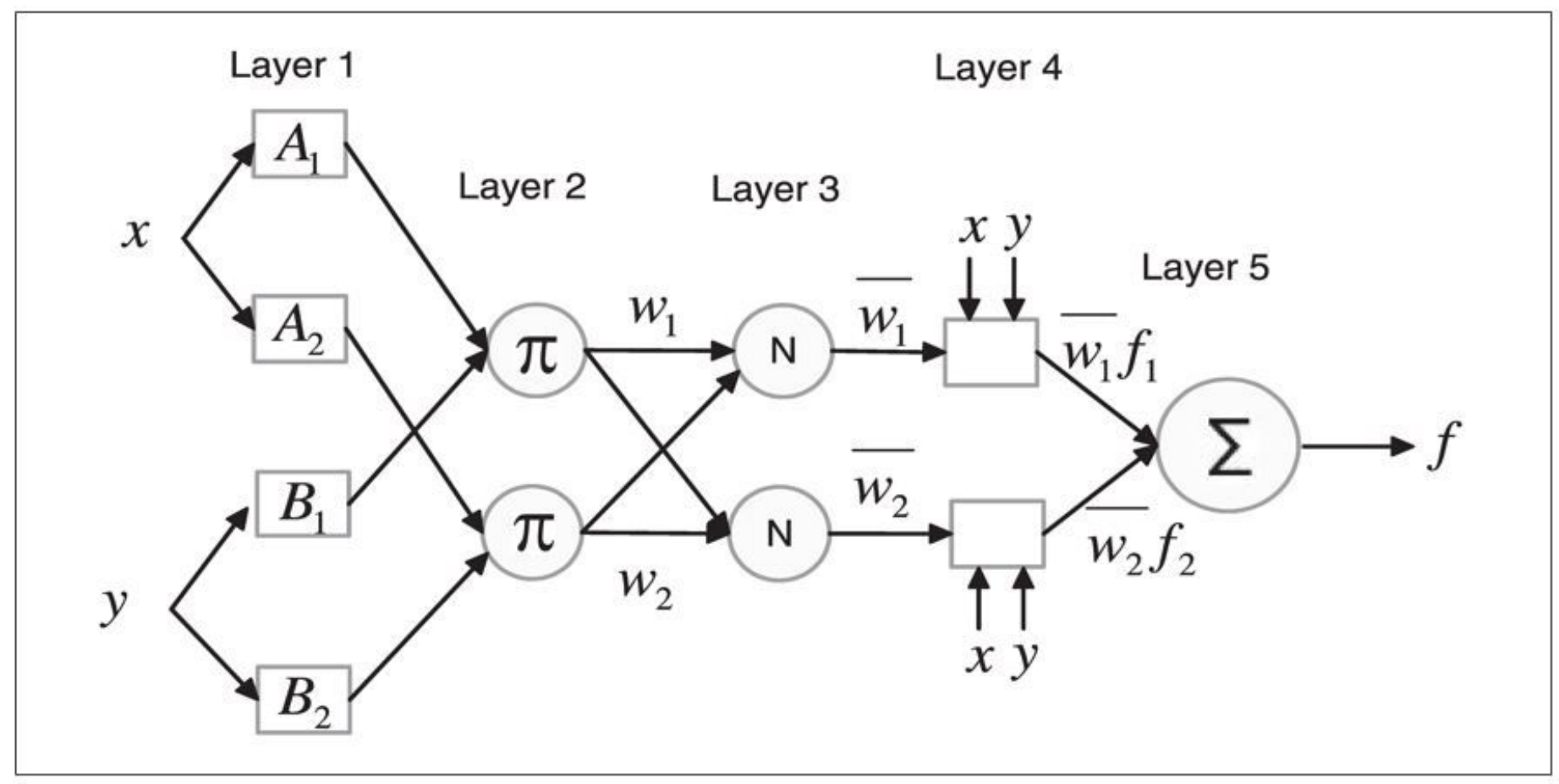

Figure 3

Schematic structure of ANFIS network 


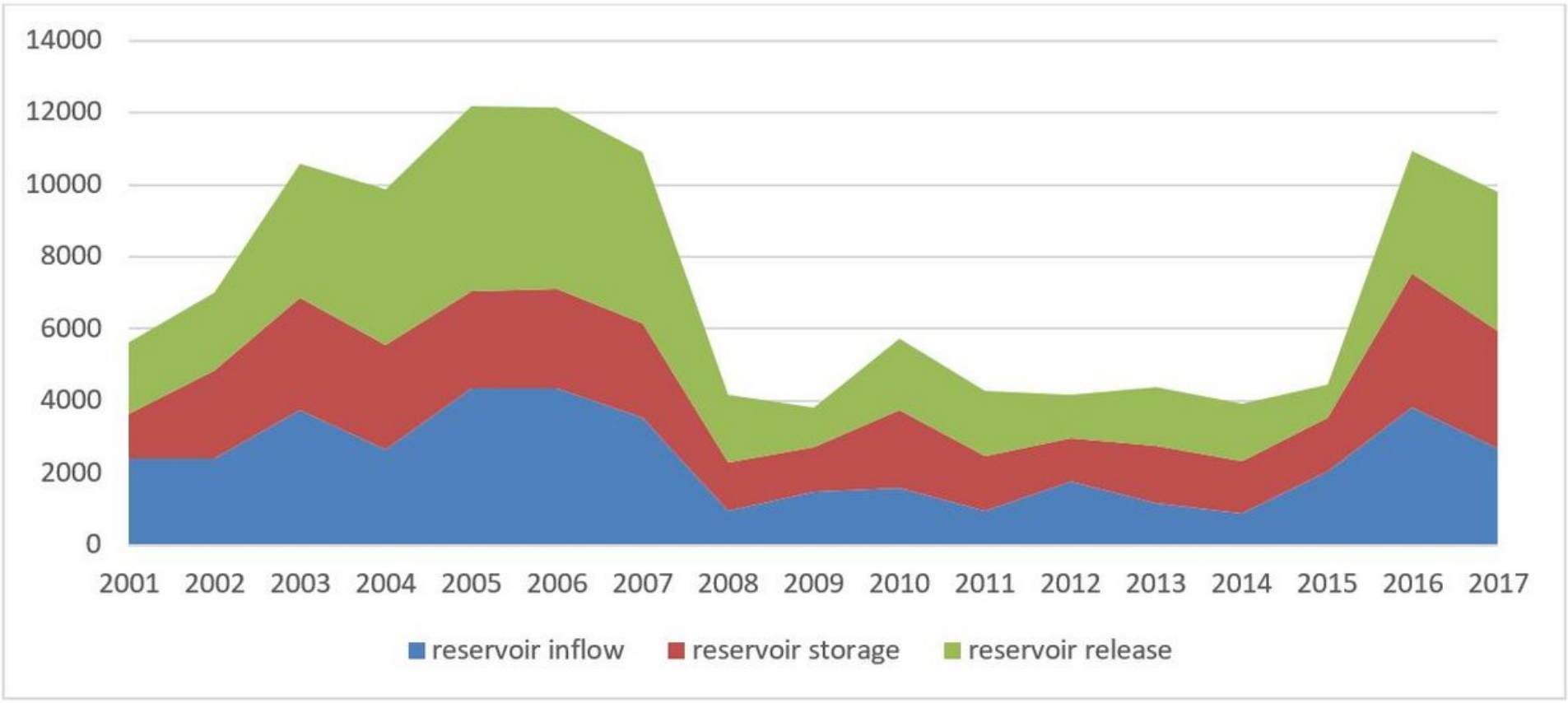

\section{Figure 4}

The trend of changes in inflow, storage and release volume of the reservoir from 2001 to 2017 

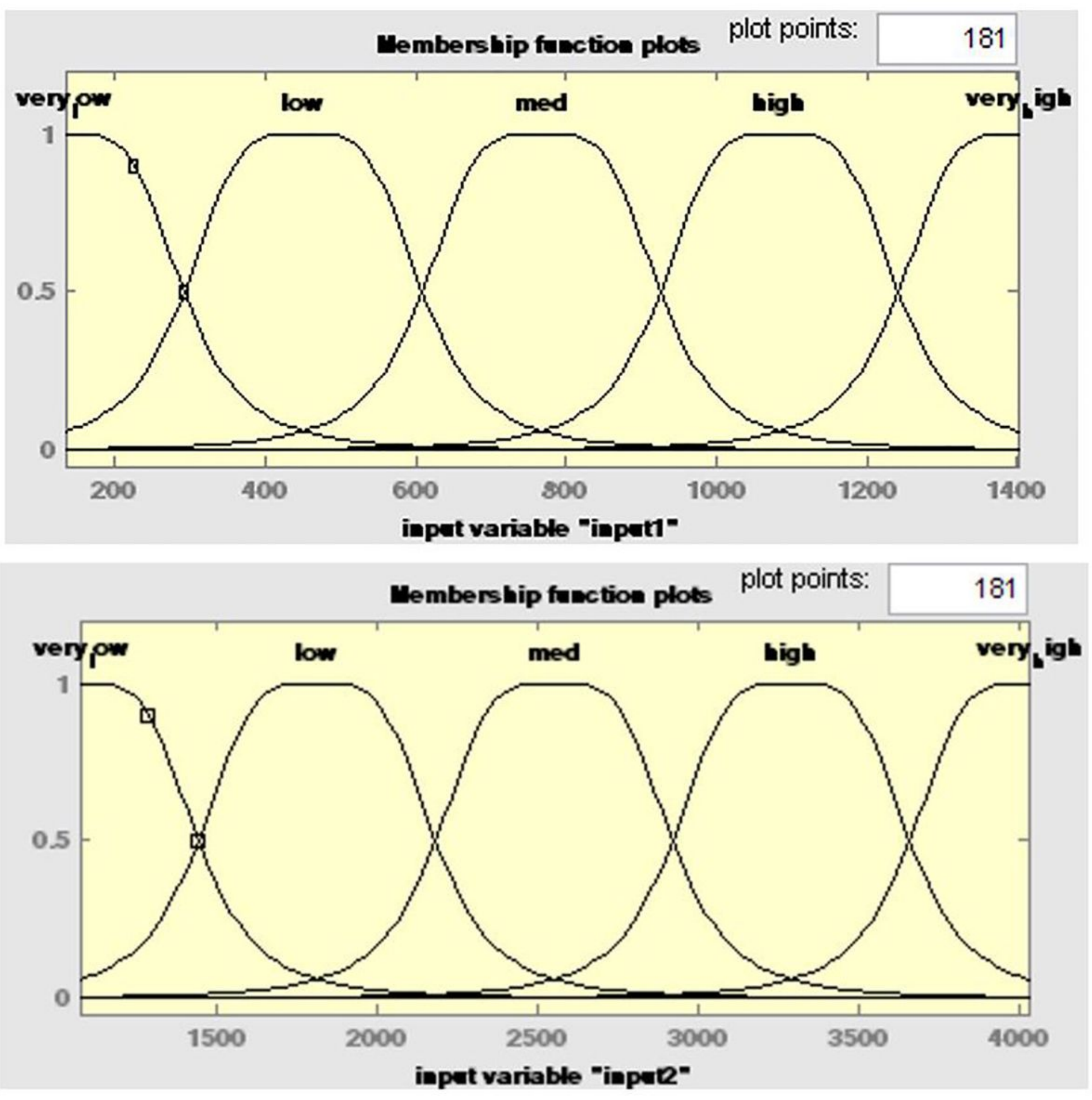

Figure 5

Membership functions of ANFIS model input variables 

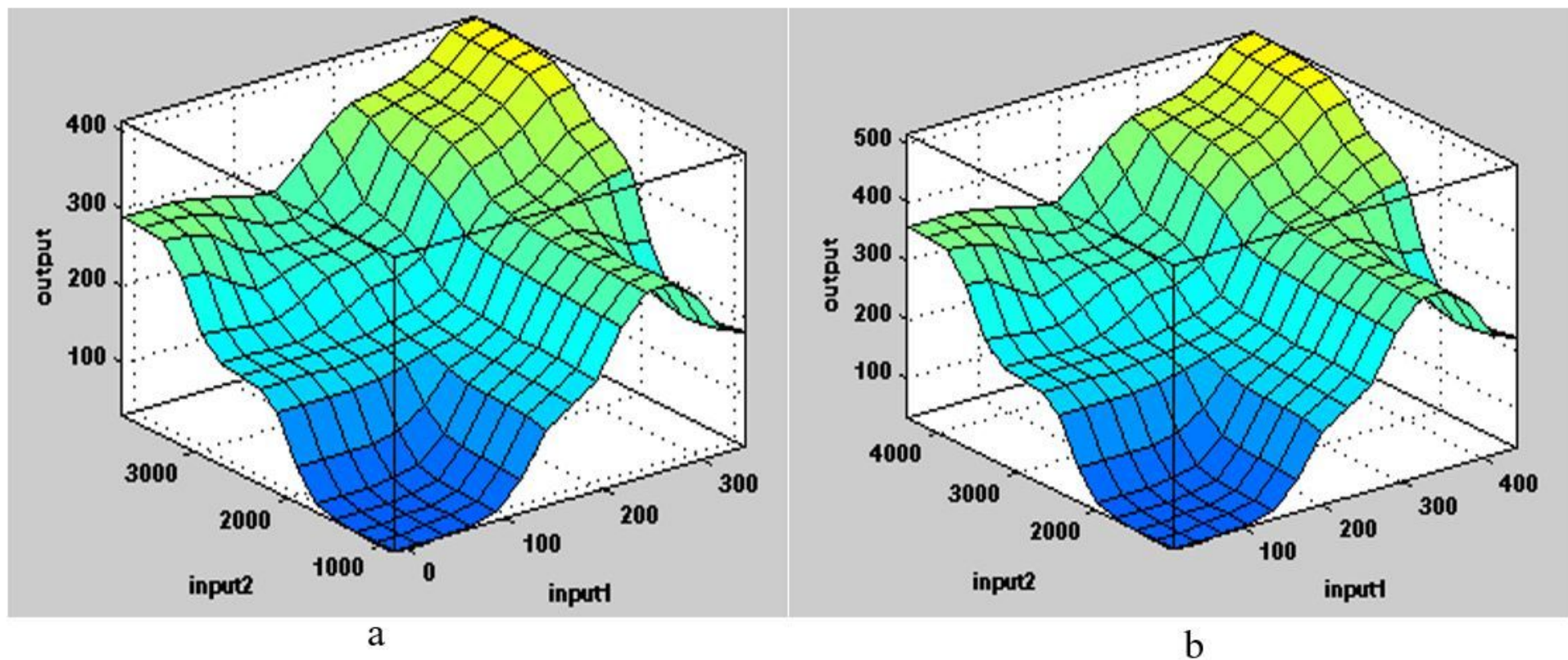

$\mathrm{b}$
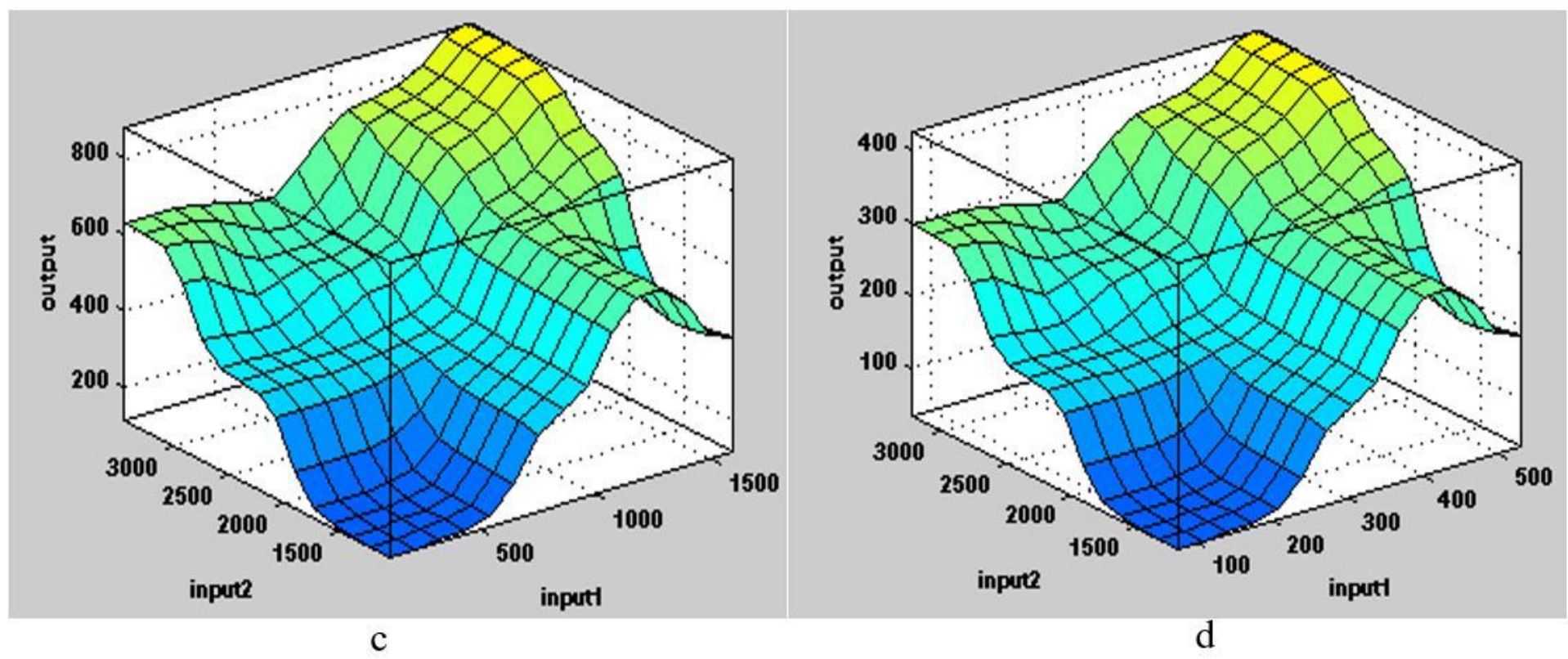

Figure 6

ANFIS model three-dimensional solution space, a: June, b: September, c: December and d: March 


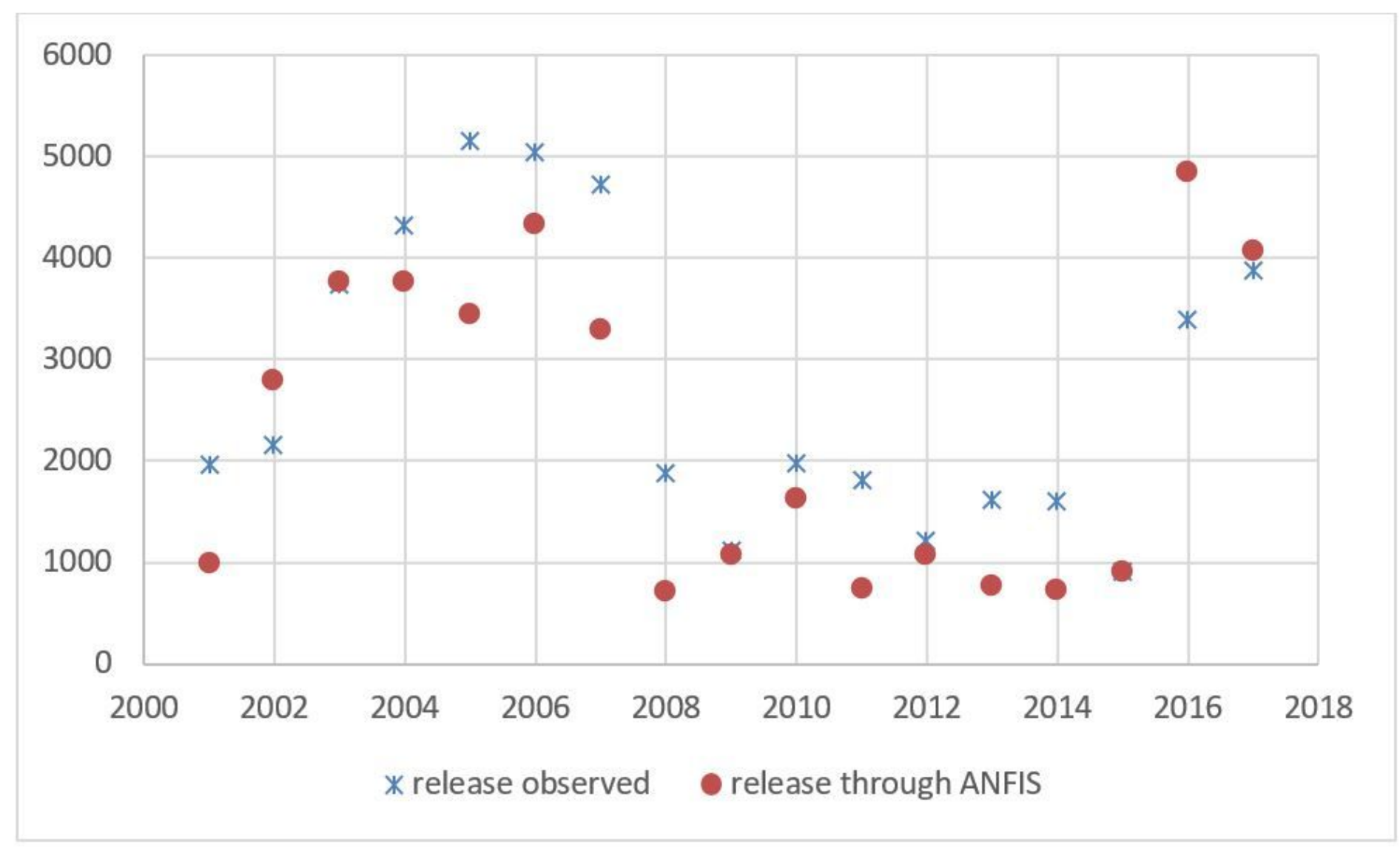

Figure 7

Comparison of observed and predicted release water volume 
200

150

100

50

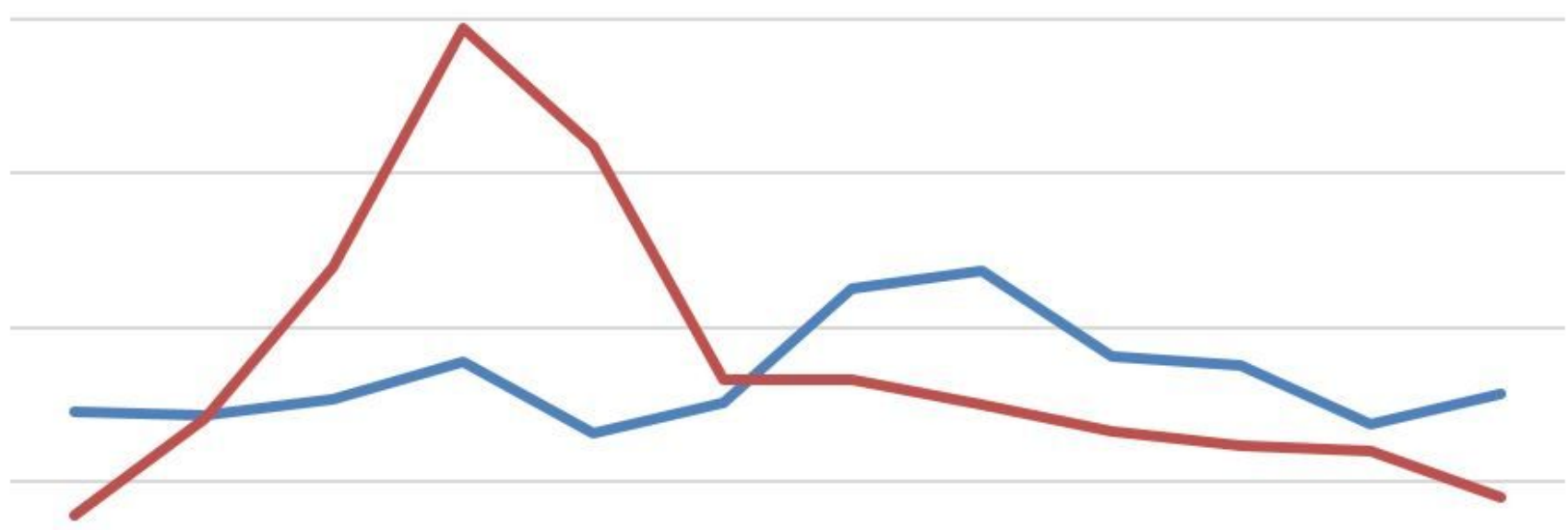

0

Jan Feb Mar Apr May Jun Jul Aug Sep Oct Nov Dec available water observed available water through ANFIS

\section{Figure 8}

Comparison of the amount of available water observed and predicted through ANFIS for the South Karkheh sub-basin

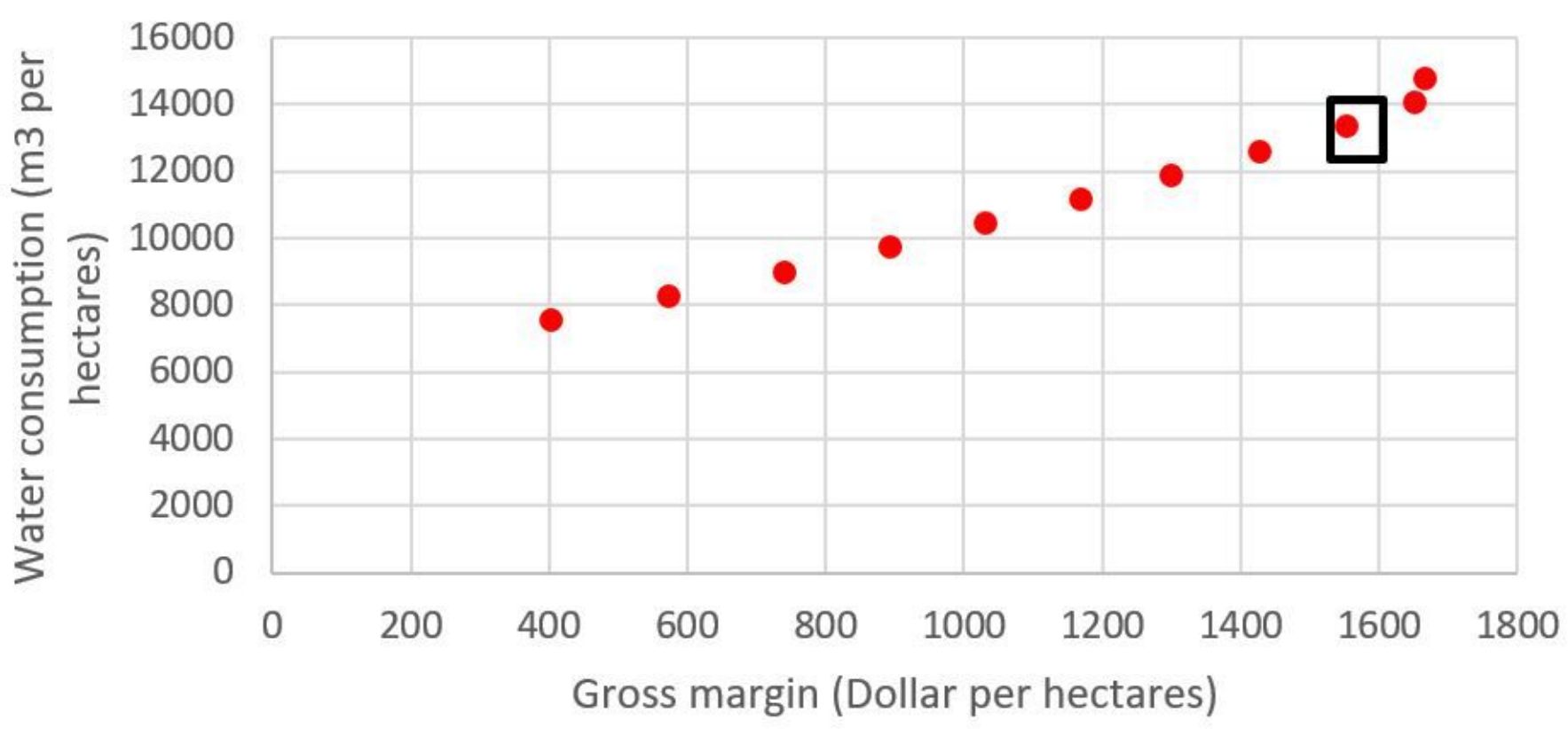

\section{Figure 9}


Total efficient solutions of multi-objective planning model and the best answer obtained from TOPSIS method
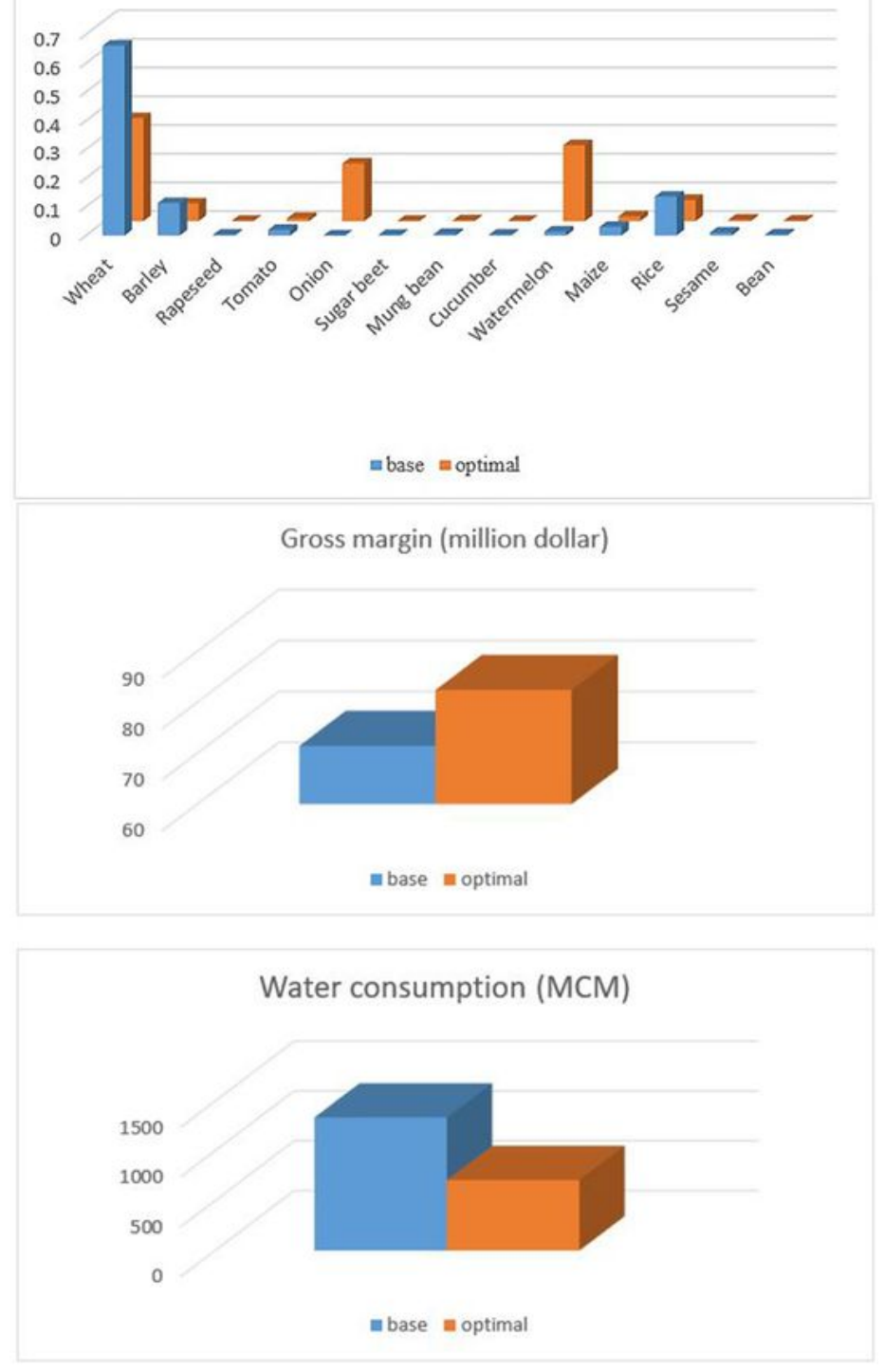

Water economic productivity (dollar per m3)

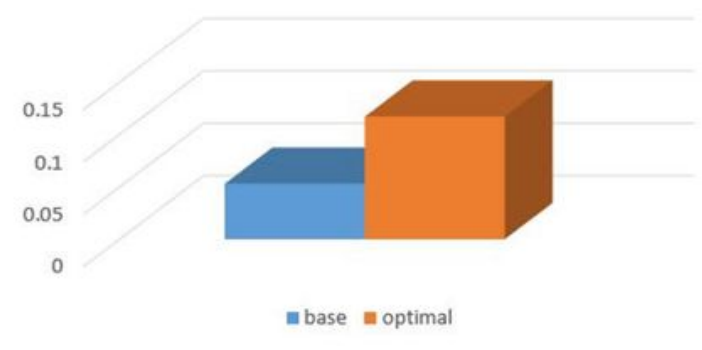

Figure 10

Comparison of crop cultivation area, gross profit, water consumption and economic efficiency of water in basic and optimal models 